\title{
Review Article \\ Silencing Viral MicroRNA as a Novel Antiviral Therapy?
}

\author{
Ugo Moens \\ Department of Microbiology and Virology, University of Tromsø, N-9037 Tromsø, Norway \\ Correspondence should be addressed to Ugo Moens, ugom@fagmed.uit.no
}

Received 28 December 2008; Accepted 20 March 2009

Recommended by Bibekanand Mallick

Viruses are intracellular parasites that ensure their existence by converting host cells into viral particle producing entities or into hiding places rendering the virus invisible to the host immune system. Some viruses may also survive by transforming the infected cell into an immortal tumour cell. MicroRNAs are small non-coding transcripts that function as posttranscriptional regulators of gene expression. Viruses encode miRNAs that regulate expression of both cellular and viral genes, and contribute to the pathogenic properties of viruses. Hence, neutralizing the action of viral miRNAs expression by complementary single-stranded oligonucleotides or so-called anti-miRNAs may represent a strategy to combat viral infections and viral-induced pathogenesis. This review describes the miRNAs encoded by human viruses, and discusses the possible therapeutic applications of anti-miRNAs against viral diseases.

Copyright (C) 2009 Ugo Moens. This is an open access article distributed under the Creative Commons Attribution License, which permits unrestricted use, distribution, and reproduction in any medium, provided the original work is properly cited.

\section{Introduction}

Viruses are common habitants of the human population, where they establish different forms of infection, including an acute, a chronic, or a persistent infection with production of low levels of virions. Some viruses can exist in a true latent state in which infectious particles are only produced upon reactivation stimuli. Viruses that reside harmlessly in their host can under certain conditions or in immunocompromised persons be responsible for malignant and nonmalignant diseases, which may even lead to the death of the host. A causal role for human polyomaviruses (HPyV), papillomaviruses (HPV), herpesviruses (HHV), hepatitis B virus (HBV), hepatitis $\mathrm{C}$ virus $(\mathrm{HCV})$, and human $\mathrm{T}$-cell lymphotropic virus type-I (HTLV-I) and cancer is accepted (for recent reviews see [1-7]). It is estimated that oncoviruses are associated with $15 \%$ of the human cancers [8], while nonmalignant infections from human immunodeficiency virus (HIV), HBV and HCV alone cause more than 3 million deaths annually worldwide [9]. Other viral infections (HIV no included) were responsible for the death of more than 6000 patients in Japan in 2006, 7000 individuals in the USA in 2005, and 555 people in United Kingdom in 2006 according the statistics of the World Health Organization
[10]. Thus the pathogenic properties of viruses necessitate the development of efficient antiviral therapies.

Viruses attempt to create a favorable cellular environment allowing viral replication or survival by establishing a lifelong latent infection through evading the immune system of their hosts. Viruses can hide within a cell by restricting their activity to a minimum so as not to conceal their presence to the immune system and at the same time they will also try to avoid apoptosis. For these purposes, viruses have developed different strategies, one of which includes the posttranscriptional regulation of both cellular and viral gene expressions through modulating the host's RNA-interference (RNAi) machinery. Viruses can suppress the RNAi pathway by viral microRNA (vmiRNA) targeting cellular or viral transcripts, or by viral proteins (e.g., human immunodeficiency virus Tat protein, influenza virus NS1/NS2 protein, Ebola VP35 protein, and vaccinia virus E3L protein) or viral RNA (Adenovirus VA transcripts) that counteract the host's RNAi machinery (for recent reviews see [11-17]). This review summarizes the recent findings on virus-encoded miRNAs and their described functions and briefly discusses the potential of antiviral miRNA as a novel therapeutic strategy in combating virus infections. 


\section{MicroRNA (miRNA)}

MiRNAs are noncoding small RNA molecules that act as posttranscriptional regulators. They seem to be an inherent part of the genomes of most living organisms as they have been described in plants, unicellular and lower invertebrates, all vertebrates, and in viruses. Their exact functions start to emerge and include control of cellular processes such as differentiation, morphogenesis, organogenesis, and metabolism [18-22]. MiRNAs are typically generated by RNA polymerase II. The primary transcript (pri-miRNA) is processed by the RNase III enzyme Drosha, in concert with double-stranded (ds) RNA-binding protein DGCR8 into a $\sim 60$ pre-miRNA hairpin. This nuclear pre-miRNA is then transported into the cytoplasma by exportin 5/RanGTP and cleaved by the cytoplasmic RNase III Dicer to generate an imperfect ds RNA of 21-25 nucleotides. One of the strands, the mature miRNA strand or guide strand, is loaded in the RNA induced silencing complex (RISC), and directs RISC to the target mRNA, where the complex hybridizes to (partially) complementary sequences resulting in cleavage or translational inhibition of the target mRNA. The unincorporated strand, called the passenger strand, is degraded. The seed region, which encompasses nucleotides 2 to 8 of the 5' ends of miRNA, plays a pivotal role in target selection by RISC-bound miRNA (for recent reviews see [23-25]). In animals, mature miRNAs do not require complete complementarity to their target mRNAs, enabling them to bind to and prevent translation of several mRNAs. Experimental evidence suggests that a single miRNA can potentially target as many as 200 different mRNAs [26-28]. As such, miRNAs have merged as pivotal posttranscriptional regulators of gene expression in multicellular eukaryotes and aberrant expression can contribute to diseases ([28] and references therein).

\section{Silencing of miRNA by Anti-miRNA Oligonucleotides}

Anti-miRNA oligonucleotides (AMOs) are chemically modified synthetic oligonucleotides that are complementary to their target sequence and this will silence the action of the target. AMOs are modified with the dual purpose to stabilize them and to improve their affinity for their targets. One modification is the 2' sugar modification which implies a chemical modification of the 2'-O of the ribose residue (Figure 1(a)). The 2'-O -methyl AMOs have a methyl group linked to the 2'-O of the ribose residue, while the 2'-O - methoxyethyl AMOs contain a methoxygroup. This modification provides improved RNase resistance and binding affinity to RNA compared to unmodified antioligonucleotides. However, 2'-O -methoxyethyl AMOs possess a higher affinity and specificity to RNA than their 2'-O -methyl AMOs. Other 2' sugar modifications that have been used include 2'-fluor and locked nucleic acid (LNA). In LNA-modified oligonucleotides, the 2'-O oxygen is bridged to the 4'-position via a methylene linker to form a rigid bicycle, locked into a C3'-end (RNA) sugar conformation (Figure 1(a)). LNAs give very strong duplex formation with their target sequences and they display excellent mismatch discrimination, hence avoiding off-target effects (for recent reviews see [28] and [29]). LNA injections against miR-122, a cellular miRNA involved in lipid metabolism, resulted in efficient and long-lasting decrease in plasma cholesterol in African green monkeys without any evidence for toxicities [30]. A second type of modification is the phosphorothioate backbone which reduces the affinity to the target somewhat, but it confers significant stability to nuclease degradation (Figure 1(b)). A third generation of antisense oligonucleotides are phosphodiamidate morpholino oligomers (PMO) in which the ribose ring is replaced with a morpholine ring. Adding an argininerich peptide $(\mathrm{RXR})_{4}$ further increased the stability and tissue retention of the PMO (reviewed in [31]). An additional modification can be made to improve the cellular uptake of the AMO. Krützfeldt et al. linked a cholesterol moiety to their AMOs and referred to these anti-miRNAs as antagomirs. Antagomirs should be $>19$ nucleotides in length to provide highest efficiency in silencing target miRNA [32-34]. The putative therapeutic potentials of antagomirs were recently demonstrated in treatment of lipid metabolic disease in animals [35]. An alternative class of AMOs is peptide nucleic acids (PNA), which are synthetic oligonucleotides with $\mathrm{N}$ (2-aminoethyl)-glycine replacing the deoxyribose or ribose backbone [36]. A study published in 2008 reported that PNA can efficiently block the action of cellular miRNAs [37]. Finally, another approach in silencing miRNA is the use of so-called microRNA sponge, a synthetic mRNA that contains multiple binding sites for a particular miRNA and that is transcribed from a plasmid containing a strong promoter (reviewed in [28]). In conclusion, different classes of AMO have been shown to be efficient in silencing miRNA and may be useful therapeutic tools (reviewed in [29, 32-34, 38]).

\section{Viral miRNAs Encoded by Human Viruses}

4.1. Human polyomaviruses. (HPyV) are nonenveloped viruses with a circular ds DNA genome of approximately 5000 base-pairs. The members BK virus and JC virus were first isolated in 1971 from the urine of a renal transplant patient with the initials B.K., and from the brain of a Hodgkin's lymphoma patient with initials J.C. who suffered from progressive multifocal leukoencephalopathy (PML), respectively. Human infections with the rhesus macaque (Macaca mulatta) Simian vacuolating virus 40 (SV40) were considered as accidental transmission of the virus from monkeys to people living in close contact with these animals or through vaccination with the contaminated poliovirus vaccines. However, recent observations support the possibility that SV40 can spread in humans by horizontal infection and even vertical transmission, suggesting that man may be a natural host for this virus. The human polyomaviruses seem to be implicated in tumours of the brain, bone, colon, mesothelium, pancreas, stomach, urogenital tract, and lymphomas and leukaemias (reviewed in [39, 40]). In 2007, two independent research groups reported the isolation of two new human polyomaviruses from nasopharyngeal 


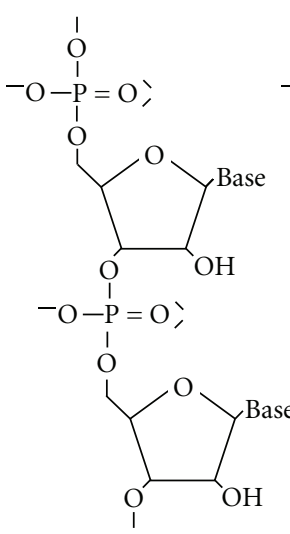

RNA

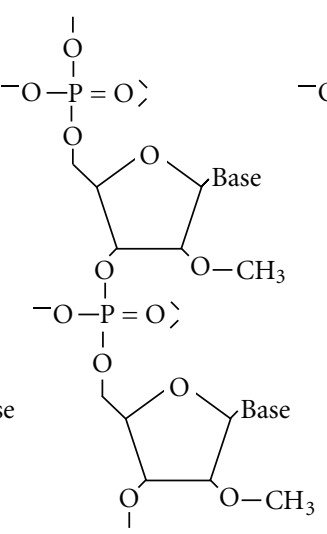

2'-O-methyl-RNA

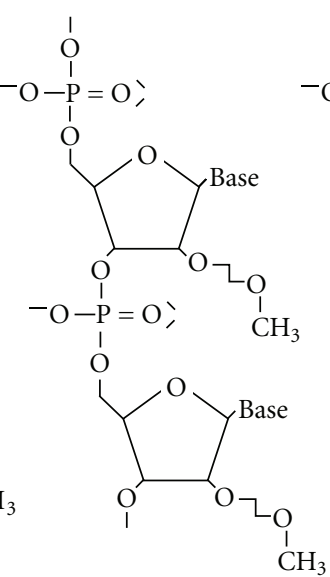

2'-O-methoxyethyl-RNA

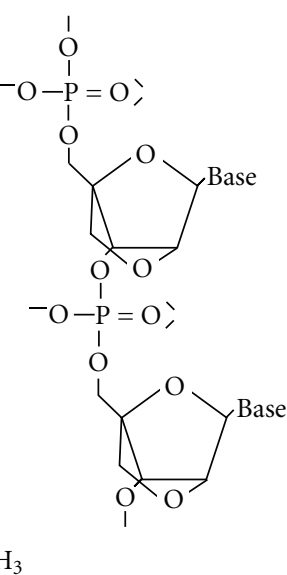

LNA

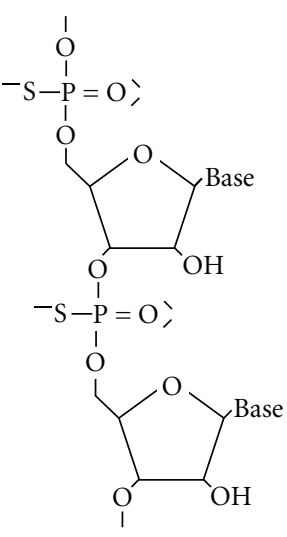

Phosphorothioate

(b)

FIGURE 1: Common chemical modifications used for anti-miRNA oligonucleotides (AMO). (A) Modifications of the 2'-O residue in ribose. (B) Modification of the phosphate-ribose backbone. LNA = locked nucleic acid. See text for details.

samples and they are referred to as KIPyV WUPyV [41, 42]. This year a novel human polyomavirus, Merkel cell polyomavirus $(\mathrm{MCPyV})$, was identified that is associated with Merkel cell carcinoma [43].

The HPyV genome can be divided into three functional regions. The early region encodes the early proteins large T-antigen (LT-ag) and small t-antigen (st-ag), while the late region encodes the capsid proteins VP1-VP3 and the regulatory protein agnoprotein. Both regions are separated by the noncoding control region that encompasses the origin of replication and the promoter/enhancer sequences for the early and late genes (reviewed in [44]). The SV40 genome encodes a viral miRNA (vmiRNA) of which both arms are complementary to the early viral mRNAs and reduces expression of the early proteins (Figure 2(a); Table 1). Cells infected with mutant SV40 lacking this miRNA or with wildtype SV40 yielded comparable levels of infectious viruses, but the latter were less sensitive to lysis by cytotoxic T cells and produced less interferon- $\gamma$. Thus SV40-encoded miRNA allows the virus to evade the immune system [45]. The SV40 miRNA is conserved in BKV and JCV and both miRNAs generated from the precursor hairpin bind to the same target, that is, the early transcripts. The BKV and JCV miRNAs serve the same role as SV40 miRNA, that is, downregulation of early expression. JCV miRNA, miR-J1, was readily detected in brain samples of PML patients, suggesting a biological role of this miRNA [46]. The group of Sullivan has also identified a MCPyV-encoded miRNA, miR-M1, which does not share sequence identity with the known miRNAs of the other polyomaviruses. MCPyV miR-M1 is located in the early region (Figure 2(a)) and can downregulate early gene expression. In accordance with SV40, this may allow the virus to evade the immune system. However, MCPyV is associated with Merkel cell carcinoma and the viral genome is integrated in these tumours [43]. Blocking miR-M1 by, for example, antagomirs will increase the expression of the viral oncoprotein LT-antigen and as such have little beneficial therapeutic effect [47]. Expression of a corresponding or other viral-encoded miRNA for the other HPyV WU and KI is lacking so far.

4.2. Human Papillomaviruses. Human papillomaviruses (HPV) are nonenveloped viruses with a circular dsDNA genome of approximately 8000 base-pairs. These viruses are associated with benign and malignant lesions of the skin and the genital tract. More than 100 different HPV genotypes have been identified and based on their association with benign warts or cancer, they are classified as low-risk and high-risk variants, respectively [1].

One study with HPV type 31 failed to clone vmiRNA from virus-infected cells [58]. However, this does not exclude that other strains may encode vmiRNA. Moreover, the expression of vmiRNA may be regulated in a temporal and spatial manner, so that the experimental conditions for capturing vmiRNA may be tricky. In addition, the high mutation rate of HPV genome sequences may impede the prediction of the presence of putative vmiRNA.

4.3. Human Adenovirus. Adenoviruses are naked dsDNA viruses that can cause mild respiratory, gastrointestinal, urogenital, and ocular disease. More than 50 serotypes have been described in human. Although there is no proof for a causative role in malignancies, adenoviruses can induce cancer in animal models and have been extensively studied to scrutinize viral mechanisms for cellular transformation [59].

Adenovirus encodes small noncoding RNAs, known as virus-associated RNA or VAI and VAII RNA, which are generated by RNA polymerase III. This noncoding RNA plays an important role for viral replication and neutralizes the antiviral action of interferon by blocking the dsRNAinduced protein kinase (PKR), which phosphorylates and thereby inactivates the eukaryotic translational initiation 


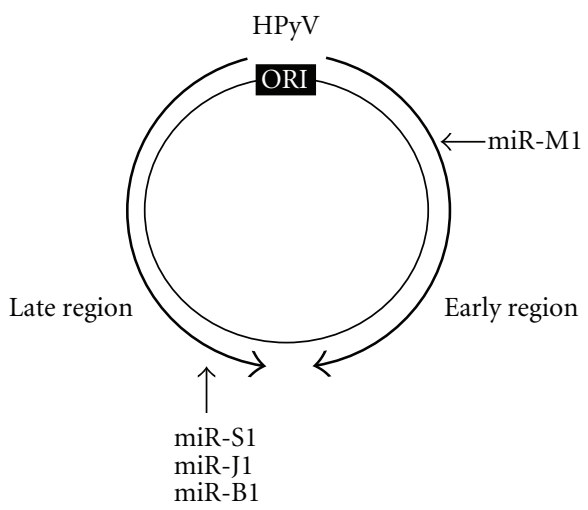

(a)
HSV-1

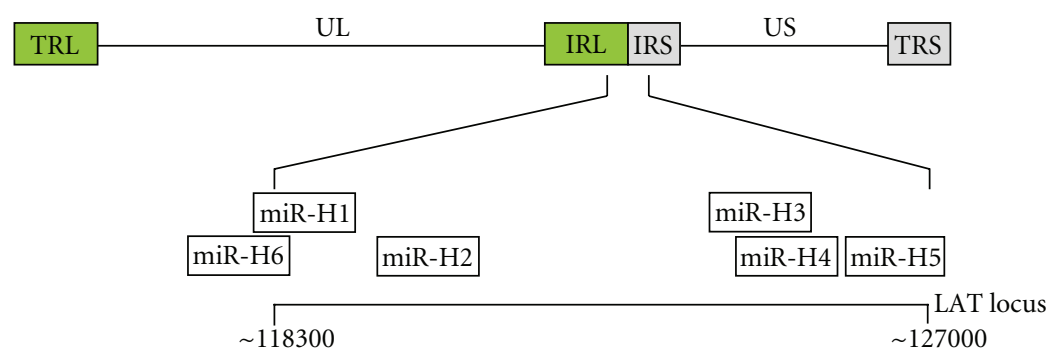

(b)

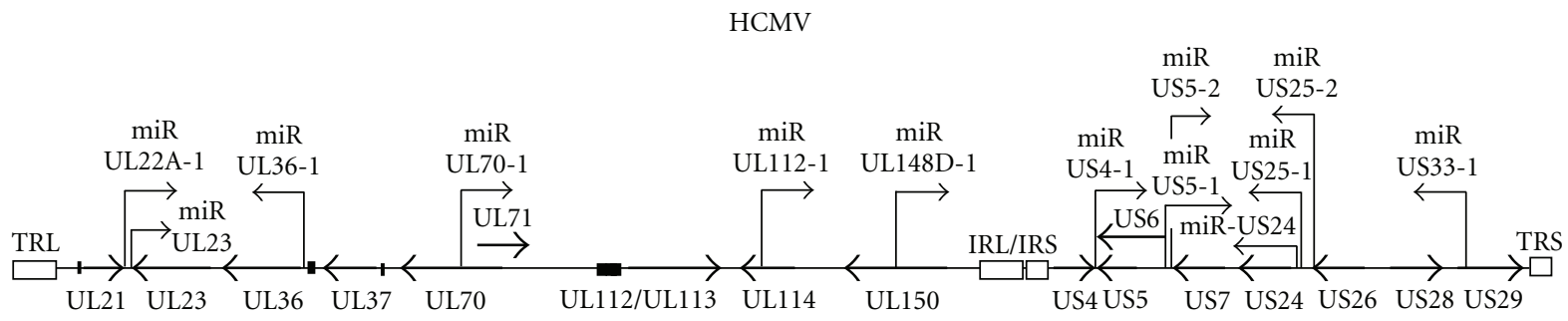

UL

US

(c)

EBV

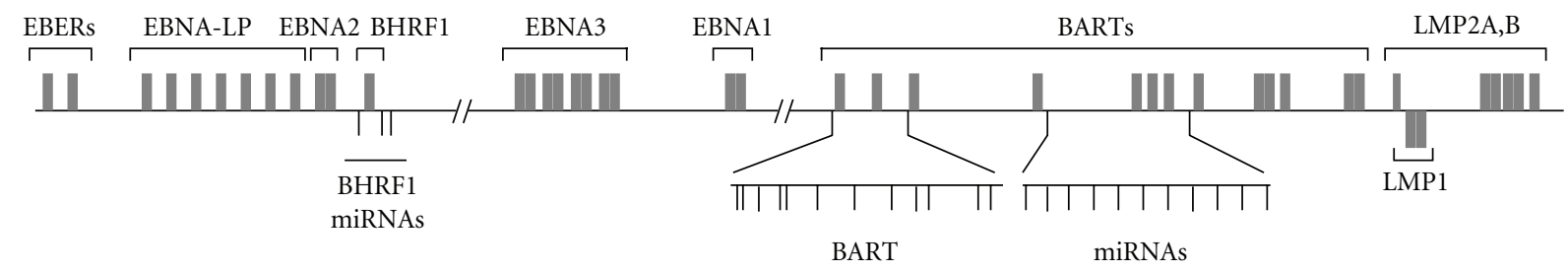

(d)

KSHV

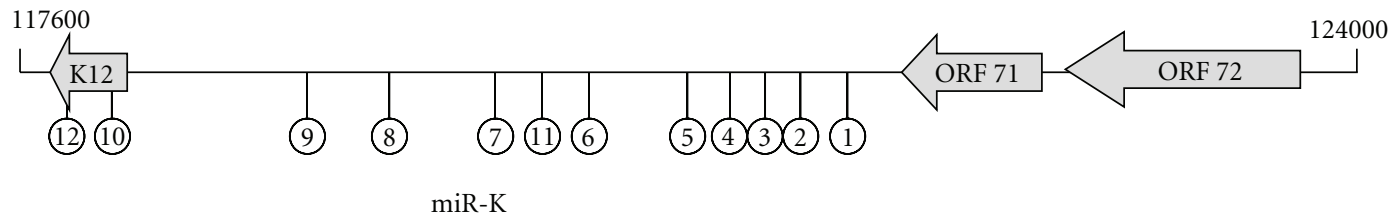

(e)

FIgure 2: Continued. 
HIV

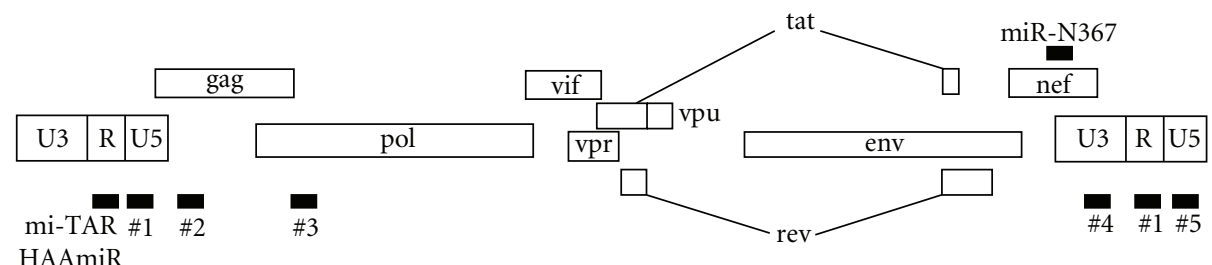

(f)

FIGURE 2: Schematic representation of the genomes of different human viruses and location of viral-encoded miRNAs. (A) The human polyomavirus (HPyV) BK virus, JC virus, SV40, and Merkel Cell polyomavirus encode the viral miRNAs miR-B1, miR-J1, miR-S1, and miRM1, respectively [45-47]. (B) Herpes simplex virus-1 genome with detail of the LATlocus. The numbers refer to the approximate sequence coordinates of the LAT locus. $\mathrm{L}=$ long, $\mathrm{S}=$ short, $\mathrm{U}=$ unique, $\mathrm{TR}=$ terminal repeat, and $\mathrm{IR}=$ internal repeat. The figure is modified after [48]. (C) Genomic map of HCMV with relative position of some of the genes. The open reading frames are depicted by thick arrows, while the position of the viral miRNAs are indicated by narrow arrows. $\mathrm{L}=$ long, $\mathrm{S}=$ short, $\mathrm{U}=$ unique, $\mathrm{TR}=$ terminal repeat, and $\mathrm{IR}=$ internal repeat. Modified after [49] and [50]. (D) Location of the miRNAs in the EBV genome. The latency genes are shown as grey boxes, while the miRNAs are indicated by vertical lines. (E) Kaposi's sarcoma-associated herpes virus (KSHV or HHV-8). Most KSHV miRNAs are clustered between the kaposin (K12) gene and the v-FLIP(ORF71) gene, while two are located within the K12 open reading frame (ORF). Adapted from [51]. (F) The HIV-1 genome and location of the viral-encoded miRNAs. The figure is based on a compilation of the studies by [52-57].

factor 2 [60]. A recent study showed that a minor fraction of VAI RNA is processed by Dicer into functional RISC-associated ssRNA which can act as miRNA (Table 1). Blocking of VAI-derived small RNA by 2'-O -methyl AMO complementary to VAI decreased virion production [61-63]. In an attempt to identify potential targets for VAI-derived miRNA, computational analysis was used. Putative targets include genes encoding apoptosis-related protein NAPOR and PKR-activating protein PACT. Therefore VAI RNAderived miRNA may help adenovirus to escape the actions of the host defense mechanisms [64].

4.4. Human Herpesviruses. Herpesviruses are enveloped dsDNA viruses with a genome size ranging between $\sim 130$ to $\sim 250$ kilobase-pairs. They are divided into three subfamilies denoted $\alpha, \beta$, and $\gamma$. Approximately 130 different herpesviruses have been identified to date, including the human $\alpha$-herpesviruses herpes simplex virus 1 (HSV-1 or HHV-1), herpes simplex virus 2 (HSV-2 or HHV-2), Varicella-zoster virus (VZV or HHV-3), the $\beta$-herpesviruses cytomegalovirus (HCMV or HHV-5), HHV-6A, HHV-6B, and HHV-7, the $\gamma$-herpesviruses Epstein-Barr virus (EBV or HHV-4), and Kaposi's sarcoma-associated virus (KSHV or HHV-8). All human herpesviruses are able to establish latent infections with only a small subset of viral genes expressed (reviewed in [64]). As will be discussed in the next section, among the viral transcripts that can be detected in latently infected cells are viral-encoded miRNAs, which seem to be required to maintain a latent state of infecton, but may also contribute to the pathogenic properties of the virus.

4.4.1. HSV-1. Herpes simplex virus-1 (HSV-1 or human herpes virus 1; HHV1) infects the majority of the human population, but remains a latent cohabitant in most people. Reactivation of the viruses usually results in cold sores, but it can also cause a spectrum of diseases from sightthreatening ocular infections in immunocompetent adults to more severe infections in newborns and immunosuppressed patients (reviewed in [89]).

An important gene in HSV latency is the LAT gene. This gene encodes the latency-associated transcript (LAT), which does not code for a protein. LAT seems to promote cell survival of the infected cells [90]. Gupta and coworkers proposed that the antiapoptotic activity of LAT was achieved by an miRNA-entrapped in the LAT (miR-LAT), which downregulates the expression of transforming growth factor- $\beta$ (TGF- $\beta$ ) and SMAD3. The latter is a mediator of the signalling pathway induced by TGF- $\beta$, while TGF$\beta$ can prevent cell proliferation and induce cell death [67]. However, a later study revealed that the described miR-LAT was not viral encoded, but in fact a cellular miRNA expressed in SH-SY-5Y cells [67] and the report describing miR-LAT was retracted [91]. Work by Umbach et al. could also not confirm the existence of this miRNA in HSV-1 infected SHSY-5Y cells [48]. Later, it was shown that the HSV-1 LAT exon encodes HSV-1 miR-LAT-ICP34.5, which can be detected in HSV-1 infected cells [89]. Circa 120 base-pairs upstream in this region, a sequence with $77 \%$ homology to the HSV-2 miRNA miR-I (see further) is present, but no mature miRNA was detected in HSV-1 infected cells. However, the existence of this miRNA during HSV-1 latency in vivo remains to be confirmed [68].

Computational analysis predicted 24-miRNA candidates in the HSV-1 genome, 8 of which were conserved in HSV2 , suggesting they may be functional miRNAs [69]. The authors confirmed the expression of one mature miRNA, designated miR-H1, in HSV-1 infected Vero cells, where it was expressed late in productive replication. This miRNA is encoded approximately $450 \mathrm{bp}$ upstream of the transcription start site of the LAT transcript, but a corresponding sequence is not conserved in the HSV-2. The function of miR-H1 
TABLE 1: MicroRNAs encoded by human viruses and their targets. See text for details.

\begin{tabular}{|c|c|c|c|}
\hline Virus & miRNA & Target/function & Reference \\
\hline \multicolumn{4}{|l|}{ Human polyomaviruses } \\
\hline SV40 & miR-S1 & $\begin{array}{l}\text { Downregulation early } \\
\text { expression; Immunomodulating }\end{array}$ & {$[45]$} \\
\hline BKV & miR-B1 & Downregulation early expression & {$[46]$} \\
\hline JCV & miR-J1 & Downregulation early expression & {$[46]$} \\
\hline $\mathrm{MCPyV}$ & miR-M1 & Downregulation early expression & {$[47]$} \\
\hline \multirow[t]{2}{*}{ Human papillomavirus } & not predicted & & {$[65]$} \\
\hline & not detected & & {$[66]$} \\
\hline Human adenovirus & unnamed & & {$[61-63]$} \\
\hline Human parvovirus & not predicted & & {$[65]$} \\
\hline \multirow[t]{8}{*}{ HSV-1 (HHV1) } & $\begin{array}{c}\text { miR-LAT } \\
\text { (within exon 1) }\end{array}$ & $\begin{array}{l}\text { Prevents apoptosis by targeting } \\
\text { translation of the genes encoding } \\
\text { TGF- } \beta 1 \text { and SMAD3 }\end{array}$ & $\begin{array}{l}{[67](\text { retracted }),[48,68,} \\
69],[70]\end{array}$ \\
\hline & $\begin{array}{l}\text { miR-LAT- } \\
\text { ICP34.5 }\end{array}$ & & \\
\hline & miR-H1 & $\begin{array}{l}\text { Repression of the expression of } \\
\text { the viral protein ICP0, which } \\
\text { promotes viral replication }\end{array}$ & \\
\hline & miR-H2 & $\begin{array}{l}\text { Downregulation of ICP } 34.5 \text {, a } \\
\text { key viral neurovirulence factor }\end{array}$ & \\
\hline & miR-H3 & $\begin{array}{l}\text { Downregulation of ICP } 34.5 \text {, a } \\
\text { key viral neurovirulence factor }\end{array}$ & \\
\hline & miR-H4 & & \\
\hline & miR-H5 & $\begin{array}{l}\text { Downregulation of ICP } 4 \text {, a viral } \\
\text { transcriptional activator }\end{array}$ & \\
\hline & miR-H6 & $\begin{array}{l}\text { Reduced expression of ICP34.5, a } \\
\text { key viral neurovirulence factor }\end{array}$ & \\
\hline \multirow[t]{3}{*}{ HSV-2 (HHV2) } & miR-I & & \\
\hline & miR-II & & \\
\hline & miR-III & & \\
\hline VZV (HHV3) & not predicted & & {$[65,71]$} \\
\hline \multirow[t]{11}{*}{ HCMV (HHV5) } & miR-UL23 & Immunomodulating & {$[12,49,65,72-74]$} \\
\hline & miR-UL36-1 & & \\
\hline & miR-UL54-1 & & \\
\hline & miR-UL70-1 & & \\
\hline & miR-UL22A-1 & & \\
\hline & miR-UL112-1 & $\begin{array}{l}\text { Downregulates the expression of } \\
\text { CMV genes involved in its own } \\
\text { replication process, for example, } \\
\text { transactivators IE72 and IE86; } \\
\text { UL120/121; UL114MHC class } \\
\text { I-related chain B (MICB), a } \\
\text { cellular ligand for the activating } \\
\text { receptor NKG2D; } \\
\text { downregulation of IE-1 }\end{array}$ & \\
\hline & miR-UL148D-1 & & \\
\hline & miR-US4-1 & & \\
\hline & miR-US5-1 & & \\
\hline & miR-US5-2 & & \\
\hline & miR-US24 & & \\
\hline
\end{tabular}


Table 1: Continued.

\begin{tabular}{|c|c|c|c|}
\hline Virus & miRNA & Target/function & Reference \\
\hline & miR-US25-1 & & \\
\hline & miR-US25-2 & & \\
\hline & miR-US33-1 & & \\
\hline & RNA $\beta 2.7$ & $\begin{array}{l}\text { Bnds components of the } \\
\text { mitochondrial respiratory chain } \\
\text { complex I and thus preventing } \\
\text { apoptosis }\end{array}$ & \\
\hline \multirow[t]{24}{*}{ EBV (HHV4) } & $\begin{array}{c}\text { miR-BART1-1 } \\
\text { to }-3\end{array}$ & Inhibition LMP1 expression & {$[24],[51,75-79]$} \\
\hline & & $\begin{array}{l}\text { Inhibit EBV DNA polymerase } \\
\text { BALF5 }\end{array}$ & \\
\hline & miR-BART2 & Inhibition LMP1 expression & \\
\hline & miR-BART3 & & \\
\hline & miR-BART4 & $\begin{array}{l}\text { Antiapoptotic by } \\
\text { downregulation of PUMA }\end{array}$ & \\
\hline & miR-BART5 & & \\
\hline & miR-BART6 & Inhibition LMP1 expression & \\
\hline & miR-BART7 & & \\
\hline & miR-BART8 & & \\
\hline & miR-BART9 & & \\
\hline & miR-BART10 & & \\
\hline & miR-BART11 & & \\
\hline & miR-BART12 & & \\
\hline & miR-BART13 & & \\
\hline & miR-BART14 & Inhibition LMP1 expression & \\
\hline & miR-BART15 & Inhibition LMP1 expression & \\
\hline & miR-BART16 & & \\
\hline & miR-BART17 & & \\
\hline & miR-BART18 & & \\
\hline & miR-BART19 & & \\
\hline & miR-BART20 & $\begin{array}{l}\text { Downregulation chemokine } \\
\text { CXCL-11 }\end{array}$ & \\
\hline & miR-BHFR-1 & & \\
\hline & miR-BHFR-2 & & \\
\hline & miR-BHFR-3 & & \\
\hline \multirow[t]{12}{*}{ KSHV (HHV-8) } & miR-K12-1 & $\begin{array}{l}\text { Downregulation of } \\
\text { thrombospondin } 1 \text { and } \mathrm{BACH}\end{array}$ & {$[51,66,75,80-82]$} \\
\hline & miR-K12-2 & $\begin{array}{l}\text { Downregulation of } \\
\text { thrombospondin } 1\end{array}$ & \\
\hline & miR-K12-3 & & \\
\hline & miR-K12-4 & & \\
\hline & miR-K12-5 & $\begin{array}{l}\text { Downregulation of } \\
\text { thrombospondin } 1 \text { and } \mathrm{BACH}\end{array}$ & \\
\hline & miR-K12-6 & & \\
\hline & miR-K12-7 & & \\
\hline & miR-K12-8 & & \\
\hline & miR-K12-9 & & \\
\hline & miR-K12-10a & & \\
\hline & miR-K12-10b & $\begin{array}{l}\text { Downregulation of } \\
\text { thrombospondin } 1 \text { and BACH-1; }\end{array}$ & \\
\hline & miR-K12-11 & Identical to miR-155 & \\
\hline
\end{tabular}


TABle 1: Continued.

\begin{tabular}{|c|c|c|c|}
\hline Virus & miRNA & Target/function & Reference \\
\hline & miR-K12-12 & & \\
\hline Poxvirus vaccinia virus & 3 predicted & & {$[65]$} \\
\hline Poxvirus variola virus & 1 predicted & & {$[65]$} \\
\hline Hepatitis B virus & & & {$[54]$} \\
\hline \multicolumn{4}{|l|}{ Hepatitis $\mathrm{C}$ virus } \\
\hline Human immunodeficiency virus & miR-H1 & & \\
\hline \multirow[t]{6}{*}{ Type 1 (HIV-1) } & miR-TAR & $\begin{array}{l}\text { HDAC-1-mediated repression of } \\
\text { viral gene expression }\end{array}$ & {$[83]$} \\
\hline & miR-TAR-5p & & {$[84]$} \\
\hline & miR-TAR-p & & \\
\hline & HAAmiRNA & $\begin{array}{l}\text { Downregulation IL-15, IL-2 } \\
\text { receptor } \gamma \text { chain, IRAK1, and } \\
\text { FMRP }\end{array}$ & {$[56]$} \\
\hline & VmiRNA\#1-5 & $\begin{array}{l}\text { Proteins involved in, for } \\
\text { example, signal transduction, } \\
\text { protein synthesis, and } \\
\text { degradation, DNA methylation }\end{array}$ & {$[85]$} \\
\hline & miR-N367 & HIV promoter interference & {$[86]$} \\
\hline \multirow[t]{2}{*}{ HIV-2 } & miR-TAR2-5p & & {$[87]$} \\
\hline & miR-TAR2-3p & & \\
\hline HTLV-I & not detected & & {$[88]$} \\
\hline Paramyxoviridae (measles virus) & 1 predicted & & [65] \\
\hline
\end{tabular}

remains to be established and no cellular target mRNAs were identified [69]. Umbach and coworkers detected in addition to miR-H1 five novel viral miRNAs in trigeminal ganglia of mice latently infected by HSV-1, as well as in HSV-1-infected Vero cells. These miRNAs, that is, miR-H1 to miR-H6, are encompassed in the LAT locus (Figure 2(b)). By quantitative RT-PCR, the authors were able to roughly estimate the number of copies of each miRNA during productive infection of Vero cells. MiR-H1 and miR-H6 were expressed at $\sim 1200$ and 300 copies, respectively, while the other miR-Hs were present at less than 40 copies per infected cell. In latently infected trigeminal ganglia, much higher levels were monitored with 63000 copies of miR-H2, 8000 copies of miR-H3, 800000 copies of miR-H4, 80000 copies of miR-H5, and 40000 copies of miR-H6. The large difference in numbers of miRNA transcripts in latently infected cells compared to cells with productive HSV-1 infection indicates that miR-Hs play an important role in establishing latent HSV-1 infection. Indeed, miR-H2 expression diminished the protein levels of ICP0, a viral transcriptional activator that promotes viral replication, while miR-H6 inhibits expression of ICP4, which is required for expression of most HSV-1 genes during reproductive infection [48].

4.4.2. HSV-2. HSV-2 typically infects the genital region and establishes a lifelong latent infection. The prevalence of latent
HSV-2 infection varies between 10-60\%. Reactivation can cause oro-facial and genital herpes, but HSV-2 infection can also cause encephalitis and neonatal herpes, and forms a risk factor for HIV acquisition [89]. The only detectable viral transcript during HSV-2 latency is the LAT, but the molecular function of this transcript remains largely unknown [92]. HSV-2 LAT exon encodes an miRNA, referred to as miRI, which is expressed during latent, as well as during acute infection. Remarkably, several promoters regulate miR-I expression in different stages of the viral life cycle. This HSV-2 miRNA efficiently diminishes the expression of the viral neurovirulence factor ICP34.5, a multifunctional protein required for viral replication in neuronal cells in vivo, and with intrinsic neurovirulent properties [93]. Thus, miR-I may affect the outcome of infection (latent versus productive) by modulating the protein levels of ICP34.5. Whether miR-I has other targets remains to be investigated, but an miR-I analogue is also expressed by HSV-1, indicating the importance of this miRNA for these viruses [68]. Tang and colleagues identified two new HSV-2 miRNAs, miRII, which includes miR-II-5p and miR-II-3p, and miR-III, both encoded by exon 2 of LAT. The expression of miR-I, II, and -III increased during infection of cells, but miR-III displayed slower kinetics than the two other miRNAs. Similar to miR-I, miR-II silences the expression of ICP34.5, while 
miR-III functionally resembles HSV-I miR-H2 in that it can downregulate the expression of ICP0 [70].

4.4.3. Varicella-Zoster Virus (VZV). VZV is a common virus that causes chickenpox or varicella during primary infection. The virus establishes a latent infection, but reactivation leads to herpes zoster, commonly referred to as shingles. Acute VZV reactivation may lead to post-herpetic neuralgia [94]. No putative miRNAs could be predicted in the VZV genome $[65,71]$, but experimental studies to unambiguously proof the existence of VZV miRNA are lacking.

4.4.4. Human Cytomegalovirus (HCMV). HCMV causes mild or subclinical diseases in immunocompetent adults, but can lead to life-threatening complications in immunocompromised patients such as organ transplant recipients and AIDS patients. In addition, HCMV is one of the leading viral causes of birth defects and has been implicated in the acceleration of long-term vascular diseases such as atherosclerosis. Depending on the tissue type and the host's immune state, HCMV can establish acute, persistent, or latent infections characterized by different viral gene expression [95, 96]. Because other herpesviruses encode miRNAs, it was assumed that HCMV may encode miRNAs which could be involved in determining the type of infection. To date, 15 HCMV vmiRNAs, scattered throughout the viral genome, have been identified (see Table 1 and Figure 2(c)). Three viral miRNAs, designated as UL23-5p, miR-UL23-3p, and miR-US24, were identified that are expressed during productive HCMV infection of permissive cells (human foreskin fibroblasts, astrocytoma U373MG cells, retinal pigment epithelial cells, and human microvascular endothelial cells). Their putative cellular target genes include genes encoding transcription factors (e.g., HNF3 and TGIF2), receptors (e.g., IL-18 receptor 1 precursor; CD206), proteins implicated in T-cell activation (AHNAK1), in signal transduction (e.g., RAB2L), and in biosynthesis of leukotrienes that sustain inflammatory reactions (coactosin-like protein). Whether these genes represent bona fide targets as well as the biological relevance of HCMV miRNA-mediated silencing of these genes remains elusive [49].

HCMV usually establishes a lifelong persistent or latent state in healthy individuals by ensuring that infected cells avoid immune recognition. The HCMV-encoded miRNA miR-UL112-1 seems to play a central role in helping the virus to hide from the host's immune system. This viral miRNA targets mRNA for MHC class I-related chain B (MICB), and to a lesser extend MICA. These proteins are cellular ligands for the activating receptor NKG2D, which is expressed on some natural killer (NK) cells, $\gamma / \delta \mathrm{T}$ cells, and CD8+ T cells. During cellular stress (such as viral infection) MICB is induced, thus activating NK-cells and T cells that can lead to the killing of infected cells. Cells infected with mutant virus lacking this miRNA were more susceptible to being killed in an NKG2D-dependent manner by NK cells [72].

The miR-UL112-1 also represses the expression of HCMV genes involved in its own replication process, in part by targeting mRNA encoding immediate early proteins. One of them is the viral transactivator protein called immediate early 72 (IE72) that regulates the transcription of viral genes required for acute replication [50]. IE72 plays a pivotal role in controlling latency and reactivation. miR-UL-112-1 can thus restrict reactivation of the virus through negative regulation of IE72 expression $[50,95]$. Two separate studies showed that miR-UL112-1 also inhibited expression of the immediate early protein IE1. Murphy et al. detected increased IE1 levels in cells infected with either a virus lacking miR-UL1121 or with mutations in the seed sequence of the iel gene compared to cells infected with wild-type HCMV [73]. Grey and coworkers demonstrated that addition of miR-UL1121 RNA prior to infection reduced IE1 protein levels and blocked viral replication [74]. IE1 is a crucial protein to ascertain lytic replication of HCMV, thus downregulation of IE1 may help the virus to establish latency. This strategy may be a common feature for herpesviruses because immediateearly genes may be putative targets for HSV-1 miR-LAT, EBV miR-BART15 and miR-BHRF1-3, and KSHV miRK12-6-3p [73]. Yet another target for miR-UL112-1 is the viral protein UL114, a homologue of the mammalian DNA repair enzyme uracyl-DNA glycosylase. UL114 is required for efficient viral DNA replication. Hence, miR-UL112-1mediated downregulation of UL114 may prevent viral DNA replication and favor a latent infection state [65]. Taken together, the actions of miR-UL112-1 seem to be associated with latent viral infection, a state which allows the virus to hide from the immune system. Ablating expression of this viral-encoded miRNAs by AMOs may therefore force the virus into a lytic cycle and provide the immune system the opportunity to get ride of the viral infection.

4.4.5. EBV. Epstein-Barr virus (EBV) or human herpsesvirus-4 (HHV-4) is a $\gamma$-herpesvirus that establishes a lifelong latent infection in B-lymphocytes in more than $90 \%$ of the human population. EBV is associated with infectious mononucleosis and has been implicated in the pathogenesis of several malignancies including Burkitt's and Hodgkin's lymphomas, posttransplant and T-cell lymphomas, X-linked lymphoproliferative syndrome, nasopharyngeal, and gastric carcinomas [97]. Latently EBV-infected cells are classified in stage I, II, or III, each of them characterized by distinct EBV gene expression [98]. Among the latency stage-specific EBV transcripts are miRNAs. More than 20 different EBV miRNAs have been identified that are transcribed during latent infection (Table $1 ;[25,51,75-79])$. The EBV miRNAs are organized in two major clusters within the EBV genome (Figure 2(d)). One cluster resides in the BART (abbreviation for BamHI-A rightward transcripts) region. The BART region gives rise to multispliced transcripts and is highly expressed in EBV-positive cancers and in epithelial tissues, while there is low BART expression in B lymphocytes. The exact function of BART mRNAs remains obscure [76]. The intronic region of BART also encodes the miRNAs miRBART1 to miR-BART20. The second region that encodes multiple miRNAs is the untranslated region of the gene encoding BHRF1 (BamHI fragment $\mathrm{H}$ rightward open reading frame 1), a viral $\mathrm{Bcl}-2$ homologue that prevents 
apoptosis. BHRF1 encompasses the miRNAs miR-BHRF-11 to miR-BHRF-1-3 [51, 75].

The expressions of EBV-encoded miRNAs in clinical samples and computational analysis to predict putative targets were applied to unravel the biological functions of EBV miRNAs. These approaches showed that the miR-BARTs are abundantly expressed in latently infected epithelial cells, nasopharyngeal carcinomas, EBV-associated gastric carcinoma cell lines and tissues, Burkitt's lymphomas latency type I, EBV positive primary effusion lymphomas, and diffuse large B-cell lymphomas, but at a significantly lower level in $B$ cells. This corresponds well with the expression pattern of BART multispliced transcripts (see above). Higher levels of BHRF1-3 were measured in latency type III Burkitt's lymphomas and in diffuse large B-cell lymphomas $[66,79$, 98-100]. Another study demonstrated that induction of EBV replication in latency I-infected cells was associated with increased expression of miR-BHRF1-1, -2 , and -3 , but expression levels of miR-BART- 1 and -2 did not change. On the other hand, induction of EBV replication in latency III-infected cells did hardly change the expression levels of BHRF1-1, -2, and -3 [98]. These observations suggest that EBV miRNAs may be implicated in the oncogenic properties of the virus, but also in regulating its replication. Moreover, a precise knowledge of the latency state of EBV and the expression pattern of viral miRNAs may improve the successful treatment of EBV infection with AMOs.

The function of most EBV vmiRNA remains poorly understood, but some targets of EBV miRNAs have been recently identified. Several mi-BARTs prevent expression of viral latent infection membrane protein 1 (LMP1) protein (see Table 1). LMP1 functions as a constitutively active tumour necrosis receptor [101], and can activate several signalling pathways including NF $\kappa \mathrm{B}, \mathrm{AP} 1$, JAK/STAT, MEK/ERK, and PKC. LMP1 can also interact with p53 and affects cyclins, cyclin-dependent protein kinases (CDK), and the CDK inhibitors p16 and p27 (reviewed in [102]). Furthermore, LMP1 is expressed in all the EBV related malignancies and promotes cellular transformation. Its oncogenic property makes LMP1 an attractive target for EBV therapy. Interestingly, overexpression of LMP1 results in growthinhibitory and sensitization to apoptosis induced by stress or chemotherapeutic agents ([76] and references therein). Thus AMO-mediated neutralization of mi-BARTs may lead to elevated LMP1 protein levels and render EBV-positive tumour cells more susceptible to chemotherapy. The viral miRNA miR-BART2 can inhibit expression of viral DNA polymerase BALF5 and may thus interfere with viral replication and prevent lytic infection $[51,77]$. Silencing miR-BART2 could thus allow the virus the complete its life cycle and produce new infectious virus particles, which then could offer the immune system the opportunity to detect and eliminate EBV. Using computational prediction programs such as miRanda and RNAhybrid (reviewed in [103]) allowed Choy and coworkers to envisage the cellular protein p53 up-regulator of apoptosis (PUMA) as a target for miR-BART5 [78]. The authors demonstrated that PUMA levels were decreased in cells expressing miR-BART5 compared to cells lacking miRBART5. In accordance, when miR-BART5 was specifically inhibited with an anti-miR-BART5 oligonucleotide, PUMA protein levels decreased and apoptosis was triggered. Thus, EBV may promote survival of infected epithelial cells by modulating the expression of an apoptotic protein through an miRNA-mediated mechanism. This finding may have important implications in the development of anti-EBV agents such as AMOs directed against miR-BART5.

Fewer studies have been directed to determine the targets of miR-BHRF1s. miR-BHRF1-2 is involved in the cleavage of BHRF1 RNA in the cytoplasm, but the biological relevance remains to be determined [98]. In another study, Xia et al. observed that high levels of miR-BHRF1-3 were correlated with low levels CXCL-11, a potent interferon-inducible Tcell attracting chemokine. MiRNA-mediated suppression of CXCL-11 may serve as an immunomodulating mechanism allowing the virus to survive in the host [79]. On the other hand, enhancing CXCL-11 expression in EBV-positive tumours by AMOs against miR-BHRF1-3 may increase susceptibility of the tumour cells to the immune system. In agreement with this, two recent studies reported antitumour activity for CXCL-11 in animal models $[104,105]$.

4.4.6. Kaposi's Sarcoma Virus (KSHV or Human Herpes Virus Type 8; HHV-8). Kaposi's sarcoma-associated virus, so named because it was detected in Kaposi's sarcoma, belongs to the $\gamma$-herpesviruses and is also known as human herpesvirus- 8 or HHV-8. HHV-8 is associated with Kaposi's sarcoma, as well as with two rare forms of B-cell malignancy: primary effusion lymphoma (PEL) and the plasma cell variant of multicentric Castleman's disease. Like other herpesviruses, KSHV can establish a lifelong latent infection characterized by a limited viral gene expression [106].

A total of $17 \mathrm{KSHV}$ miRNAs encoded by 12 distinct miRNA genes have been reported and their sequences are highly conserved between different KSHV genomes in PEL cell lines and in clinical samples. However, some polymorphism was observed, particularly in miR-K12-5 and miR-K12-9 [80, 107, 108]. The entire KSHV miRNA cluster resides within an approximately 4 kilobase-pairs region between open reading frames ORF K12 (kaposin) and ORF 71 (Figure 2(e)).

To elucidate the functions of the KSHV miRNAs, transcriptome analysis was performed from cells stably expressing the miR-K12 cluster. Among the differentially expressed genes were genes encoding proteins implicated in proliferation, immune modulation, angiogenesis, and apoptosis. The gene encoding thrombospondin-1 was targeted by all ten KSHV miRNAs, but especially by miRK12-1, miR-K12-3-3p, miR-K12-6-3p, and miR-K12-11. Thrombospondin-1 possesses antiproliferative and antiangiogenic properties. Other transcripts that were reduced corresponded to the genes for osteopontin, S100 calcium binding protein, plasticity related gene 1 product, and integral membrane protein $2 \mathrm{~A}[80,81]$. The mRNA for the $\mathrm{Bcl}-2$ interacting protein BCLAF1 was identified as a target for miR-K12-5. Additional inhibition of BCLAF1 expression was obtained in the presence of miR-K9, $-10 \mathrm{a}$, and $-10 \mathrm{~b}$. The 
exact biological relevance is not yet understood, but siRNAmediated depletion of BCLAF1 enhanced the frequency of spontaneous lytic reactivation of KSHV. MiRNA-mediated reduction of BCLAF1 expression would prevent permanent latency of the virus, a type of infection that represents a deadend pathway of viral spreading $[108,109]$.

A KSHV miRNA that has gained special interest is miRK12-11 because its seed sequence, known to be critically important for mRNA target recognition is $100 \%$ conserved with the cellular miR-155, suggesting that these miRNAs may regulate common targets. The exact role of miR-155 remains unclear, but a number of B-cell lymphomas and solid organ tumors overexpress miR-155, while miR-155 transgenic mice develop B lymphomas [110, 111]. Work by the groups of Skalsky and Cullen confirmed that miRK12-11 indeed is an orthologue of miR-155, and that they target common transcripts [81, 82]. Comparing the gene expression profiles in cells stably expressing either miR-155 or miR-K12-11 revealed that they regulate an analogous set of mRNAs. The products of these transcripts include proteins involved in B-cell function (e.g., Src-like adaptor or SLA), innate immunity (e.g., I $\kappa \mathrm{B}$ kinase and phosphoinositide3-kinase), apoptosis (XIAP associated factor-1; LDOC1), cell cycle regulation (e.g., FOS), and gene expression (e.g., FOS and BACH1). BACH-1 ( $\underline{B}$ tb and $\underline{\mathrm{CNC}}$ homolog 1) is a bZip protein that can repress transcription through heterodimerization with the small Maf proteins [112], while c-Fos can heterodimerize with the JUN proteins to form the AP-1 complex. AP-1 is a multifunctional protein involved in cellular proliferation, transformation, and apoptosis [113]. For a complete list of miR-155/miR-K12-11 regulated genes, the reader is referred to the work of Skalsky et al., and of Gottwein et al. [81, 82]. Treatment of latently-infected KSHV with an antagomir against miR-K12-11 enhanced Fos protein levels about 2.5 -fold compared to untreated cells [81]. Computational analyses further revealed seed sequence homology between the viral miRNAs KSHV miR-K12-6-5p, EBV-BART5, and HCMV UL70-5p with human miRNAs miR-15a plus 16 , miR-18a/b, and miR-340, respectively [82]. Both miR-15a and miR-16 are believed to possess tumour suppressor activity and to induce apoptosis by silencing Bcl2 expression, while miR-18 was demonstrated to be oncogenic $[52,114]$. KSHV-encoded miRNAs seem to be crucial both in survival of the virus in its host, but also to play a causal role in viral-associated pathologies. AMO-mediated silencing of KSHV-encoded miRNAs may thus be a strategy to counteract viral infection, but may also undesirably target cellular miRNAs with identical seed sequences as the viral miRNAs.

4.5. Poxvirus. Poxviruses are dsDNA viruses that replicate in the cytoplasm and have as such no access to the nuclear proteins involved in the biogenesis of miRNA. Nevertheless, miRNA precursor sequences have been predicted in the genomes of the human poxviruses vaccinia virus and variola virus, but their existence has not been validated $[25,65]$. Whether the other human poxvirus, molluscum contagiosum virus, encodes miRNA remains to be established.
4.6. Hepatitis B Virus. Hepatitis B Virus (HBV), an enveloped virus with a circular partial dsDNA genome, persistently infects more than 300 million people worldwide. HBV can cause a spectrum of liver diseases ranging from mild liver dysfunctions to chronic hepatitis, cirrhosis, and hepatocellular carcinoma [53]. This makes efficient antiHBV therapy highly vital. AMO-based vmiRNA silencing is probably no option since no miRNAs could be detected by computational analysis [65], and expression of HBV miRNAs has not been reported so far. One study identified a putative HBV-encoded miRNA, but in vivo expression of this HBV miRNA was not tested. Computational screening for complementary sequences in the 3' untranslated regions of cellular mRNA to this HBV miRNA did not reveal putative target transcripts [54]. It therefore seems unlike that this is a bona fide viral miRNA.

4.7. Human Immunodeficiency Virus (HIV). HIV is the causative agent of acquired immune deficiency syndrome (AIDS), and it is estimated that $>30$ million people worldwide are infected with this virus. Two species, HIV-1 and HIV-2, infect humans (for a recent review see [55]).

HIV utilizes reverse transcriptase to convert its ssRNA genome into a dsDNA provirus. During this process, the 5' and 3' ends of the viral RNA genome are converted into long terminal repeats (LTRs). The LTRs play a pivotal regulatory role in establishing, maintaining, and overriding the latent state of the virus [115]. The central domain of the LTR is referred to the $\mathrm{R}$ region, which encompasses the (transactivation-response region) TAR. TAR binds the viral protein Tat, a transactivator that plays an important role in the transcriptional activation of the provirus genome (reviewed in [116]). The TAR encodes proven and putative miRNAs (Figure 2(f)). Klase and coworkers described an miRNA encoded by the HIV-1 TAR element. This miRNA causes HDAC-1 to associate with the viral LTR, resulting in diminished viral gene expression. This suggests a role for HIV-1 miRNA in maintaining viral latency [83]. In another report, Ouellet and colleagues demonstrated the expression of two TAR element-derived miRNAs by Northern blotting, primer extension, and RNase protection assay. The miRNA derived from the left arm of the TAR stem has been named miR-TAR-5p, while the miRNA originating from the right arm was designated miR-TAR-3p. The latter appears to preferentially accumulate in HIV-positive cells [84]. The biological role of these miRNAs remains to be elucidated, but they may contribute to modulating viral and/or cellular gene expression, with a potential impact on viral replication and/or host antiviral defense efficiency. The miR-TAR-5p described by Ouellet overlaps with the vmiRNA no. 1, while miR-TAR-3p partially overlaps with vmiRNA no. 5 described by Bennasser and coworkers [85]. They predicted by computer-directed analyses 5 pre-miRNAs in the HIV-1 genome, which in principle could yield 10 mature miRNAs. Their expression has not been validated, nor has their biological role been addressed, but deduction of potential target transcripts resulted in the indentification of cellular genes encoding protein kinases, ion channels, 
proteins involved in protein synthesis and degradation, growth factors, and DNA methylation [85]. TAR DNA of the long terminal repeat of HIV-1 encompasses an antisense RNA (HIVaINR), which encodes HIV proteins, but that can also form a duplex with the 5' end of all sense HIV mRNA, enabling the virus to control the expression of its gene [117]. HIVaINR can potentially code for several miRNAs, referred to as HAAmiRNAs. Putative targets for these miRNAs are the mRNAs for interleukin (IL)-15, IL-2 receptor $\gamma$ chain, human fragile $\mathrm{X}$ mental retardation protein (FMRP), and IL-1 receptor-associated kinase 1 (IRAK1). IL-15 is important in the regulation of T-cell maturation, development and survival of natural killer cells, and survival of long-lived memory T cells, while the IL-2 receptor $\gamma$ chain is a common component of the receptors for IL-2, $-4,-7$, $-9,-15$, and -21 . Aberant expression of this receptor leads to severe T-cell and NK-cell deficiencies. IRAK1 is a critical signalling mediator of innate immunity. Downregulation the expression of IL-15, IL-2 receptor $\gamma$ chain, and IRAK1 by HIV miRNA would impair the immune system and favor survival of the virus in the host. FMRP is an RNA-binding protein that is implicated in protein synthesis and miRNA processing. Thus HIV could use HAAmiRNA to deregulate the host miRNA mechanism to dispose the virus by depleting FMRP ([56] and references therein.) Although the existence of these HAAmiRNAs has not been proven, it is tempting to speculate that, in accordance with other viruses, HIV encodes miRNAs allowing HIV to survive in the host. A recent study examined the possibility of HIV-2 TAR to encode miRNAs. Two putative miRNAs, miR-TAR2-5p and miR-TAR-3p were identified, but their expression awaits validation [87].

Besides TAR, other regions of the HIV genome have been shown to contain miRNA sequences. The nef gene of HIV1 is located at the 3 ' end of the viral genome and is highly expressed during the early stages of virus replication. Nef is a multifunctional accessory protein that is important for viral replication, but that also plays a key role in pathogenesis as Nef can downmodulate CD4, CD28, and the class I major histocompatibility complex [86]. HIV-1 encodes a $n e f$-derived miRNA referred to as miR-N367 (Figure 2(f)). Unlike classical miRNA, this miRNA does not affect gene expression at the post-transcription level, but rather at the transcription level by promoter interference. MiR-N367 suppresses HIV-1 promoter activity via a negative responsive element in the 5'-long terminal region and via Nef sequences in the 3' untranslated region $[57,118]$. Future studies are required to elucidate the precise mechanism by which miRN3667 represses HIV-1 promoter activity. Downregulation of Nef expression may suppress HIV-1 replication and allow persistently low pathogenic or latent viral infection [57]. As the nef gene is conserved in HIV-2, HIV-2 may also apply a similar mechanism to maintain a low profile in the host.

The identity and action of HIV miRNAs remains to be scrutinized before AMOs-based therapy can be considered as anti-HIV drugs. However, computational alignment of the potential HIV-1 miRNAs with specific human T-cell mRNAs identified potential cellular targets including genes encoding CD4, CD28 and interleukin-2, IL-3, and IL-12 [119]. Viral miRNA-caused inhibition of the expression of these proteins seems advantageous for the virus, and therefore counteracting vmiRNA by AMO may help the host to clear HIV infection.

4.8. Human T-cell leukaemia virus type 1 (HTLV-I). HTLVI persistently infects 10-20 million humans worldwide and is the etiological agent for adult T-cell leukaemia [5]. One study reported that T cells persistently infected with HTLV-1 did not express viral microRNAs [88], but meticulous studies should be performed to rule out the existence of HTLV-I miRNA.

4.9. RNA Viruses. Pfeffer et al. tried to identify miRNA in the genomes of human RNA viruses like Marburg and Ebola virus (Filoviridae), measles virus (Paramyxoviridae), poliovirus (Picornaviridae), yellow fever virus and hepatitis $\mathrm{C}$ virus (HCV; Flaviviridae), and Sindbis virus (Togaviridae). None of these viral genomes seem to contain putative miRNA sequences, except for measles virus and yellow fever virus, which each possesses a single putative miRNA. However, the miRNA in yellow fever virus could not be validated, while the existence of miRNA in measles virus was not tested $[25,65]$. Intriguingly, the liver-specific miR-122 facilitates the replication of the oncovirus HCV, but the mechanism for this function of miR-122 in HCV replication is still unknown $[120,121]$.

\section{Conclusions}

Numerous human diseases are caused by viral infections, but the intimate relation with the host makes the development of antiviral drugs difficult. Vaccination has been proven to be very succesful to combat some viral infections, but mutations and diversity of virus strains has hampered the development of efficient vaccines against other viruses. New antiviral treatments are based on drugs that inhibit specific viral activities such as viral proteases or polymerases (for recent reviews see $[122,123])$. Viral-encoded miRNA that may be implicated in the viral life cycle and the pathogenic properties of the virus offers a novel attractive target for antiviral therapy. Silencing the action of viral miRNAs may enable the host cell or the immune system to gain control over the virus and even to eliminate the virus. The idea of targeting viral transcripts is not new, and RNA interference has been demonstrated to efficiently mediate inhibition of replication of human pathogenic viruses such as HIV-1, HCV, dengue virus, severe acute respiratory syndrome (SARS) coronavirus, poliovirus, human rhinovirus, influenza A virus, hepatitis D virus, HBV, HSV-1, HPV, JCV, EBV, and CMV in cell culture (reviewed in [12]). Besides recent studies have proven the potential of this RNA interference as antiviral therapy in animal models $[124,125]$, and even in clinical trials such as Alnylam against respiratory syncytial virus and NUC B1000 against HBV (reviewed in [126, 127]). However, anti-HIV RNA interference studies revealed that escape virus variants could appear which could evade the inhibitory action of siRNA $[128,129]$. 
The use of AMO to neutralize viral miRNA adds a new twist to RNA interference. AMOs are easy to produce and relatively cheap, and easy to administer locally (but not systemically). Moreover, they possess low toxicity and are highly specific. Most viral miRNAs identified so far have little homology to each other and to known host cell miRNAs (reviewed in [130]). This reduces the risk of offtarget effects of anti-miRNA oligonucleotides and increases the therapeutic potentials of miRNA silencing. The miRNA silencing action of both LNA and antagomirs is sensitive to single nucleotide exchanges. For antagomirs, it was shown that this effect depends on the position of the mismatch. Nucleotide substitutions at the very 5' end or in the centre did not prevent downregulation of miR-122 [33]. These data indicate that changes in the 3 ' end of the antagomir may abrogate its ability to destroy target miRNA and should be taken into account when designing and testing antagomirs. Another advantage of AMOs is that they probably can be used against all serotypes of a specific virus. Although not meticulously investigated, miRNA sequences between different viral strains seem to be conserved because of their importance for the viral life-cycle (see e.g., KSHV-encoded miRNAs; $[80,107,108]$ ). However, polymorphism in viral miRNAs has also been observed (see next paragraph).

Although AMOs may provide an attractive novel antiviral therapy, practical problems and other pitfalls may hamper the use of them. For example, antagomirs directed against miR-UL-112-1 could drive the virus towards acute replication and disrupted the inhibition of MCIB expression, resulting in possible clearance of the virus by the immune system. However, there is a potential risk of severe pathological effects caused by acutely replicating HCMV, especially in immunocompromised patients [50]. Another disadvantage of AMOs may be off-target effects. As miRNA do not require full complimentarity to bind their target sequence, it can be imagined that an AMO not only binds to its predicted miRNA but also to other miRNAs and even mRNAs. In addition, ssRNA oligonucleotides may interact with Toll-like receptors 7 and 8 thereby stimulating the immune system. Similar side effects have been reported for siRNA (reviewed in [126]). Polymorphism in viral-encoded miRNAs has been described in viral-infected cell lines and in clinical samples. For instance, miR-K12-5 of different KSHV isolates contains mutations, which can affect maturation and biological activity of this miRNA $[25,100,107]$. Thus the miRNA may not be expressed, in which case the AMO will have no effect or the AMO may not bind because of the mutations in its target miRNA. Another problem facing the use of AMOs in antiviral therapy is that the expression of a specific gene may be regulated by several viral miRNAs. For example, translation of the transcript of theBACHgene is prevented by three KSHV viral miRNAS: miR-K12-11, miRNA-K12-1, and miR-K12-6. Thus the effectiveness of an AMO against, for example, miR-12-11 can be compromised. Indeed, treatment of latently infected KSHV virus with a specific antagomir against miR-K12-12 alone only modestly increased the amount of $\mathrm{BACH}$ protein [81]. A cocktail of different AMOs directed against distinct viral miRNA may help to overcome this problem. So far, such studies are lacking, but a recent study successfully applied sponge miRNA to silence HBV transcripts. An expression vector encoding multiple miRNAs targeting HBV HBsAg mRNA strongly reduced the expression of this protein [131]. Another challenge is to improve in vivo delivery of the AMOs to viral infected cells and obtain long-lasting action of the antagomirs. Aerosol delivery devices similar to the ones used for delivery of asthma therapeutics could be used for respiratory viruses [15]. Other delivery strategies include intravenal or systemic injection, viral vectors, and lipid- and polymerbased vehicles [131-134]. Recently, sustained inhibition of HCV replication in cell-culture was obtained when celldegradable multilayered polyelectrolyte film (MPF) coated with siRNA was delivered to infected cells. By this approach, a single regime of MPF-mediated siRNA treatment was sufficient to inhibit HCV replication for 12 days. Moreover, MPF-mediated delivery of siRNA also protected uninfected cells from HCV infection. Another advantage is the very low toxicity of MPF [135]. These promising observations in cell culture put MPF-based delivery of AMOs forward as an efficient antiviral tool. Another limitation of anti-miRNAs is the site of application. Studies with antagomirs against miR-16 in mice revealed that when injected into tail veins, antagomirs were incapable of silencing miR-16, whereas local injection into the mouse cortex efficiently induced degradation of the target miRNA [33]. Another drawback of the use of AMOs is that the chemical modification can exert antiproliferative or other off-target effects such as been demonstrated for the phosphorothioate backbone, which can associate with cellular proteins [29].

Antisense oligonucleotides such as LNA and PMO have proven to efficiently inhibit RNA and DNA virus replication in cell culture and animal models, without toxicity for the cell or animal. However, these PMO were directed against viral protein-encoding mRNA, and studies of PMO-mediated silencing of viral miRNA have not been reported so far (see e.g., [31, 136-138]). Future viral miRNA research is faced with important challenges before AMOs may enter the clinic. Our comprehension on the functions of viral miRNA and the interplay between viral infection and cellular miRNA expression is just beginning to emerge. Studies aimed at the identification of viral miRNA and elucidation of their functions should be pursued. Difficulties facing computational-based prediction are false positives, but also the shortcoming to detect genuine miRNAs. Moreover confirmation of expression of miRNA by, for example, Northern blot may fail to monitor miRNA. Expression levels of vmiRNA may be cell-specific, for example, EBV miRBHFR1-2 had considerably lower expression levels in Jijoye cells than in B95-8 cells [7]. Dose- and time-dependent studies are required to determine the optimal therapeutic regime. Such pharmacokinetics and pharmacodynamic studies are largely lacking [133], but recent in studies in mice revealed that a single cerebral or tail-vein injection of $240 \mathrm{mg} / \mathrm{kg}$ body mass anti-miR122 had a silencing effect for at least 8 days and as long as 23 days in the tissues examined $[32,33]$. In another study, a five-week regime of two intraperitonal or subcutaneous injection a week with different concentrations of anti-miR-122 clearly silenced miR-122 and no untoward 
effects were observed [35]. Despite the obstacles facing antiviral miRNA silencing as viral therapy, the coming years will certainly see the daylight of intensified research and even the initiation of clinical trials.

\section{References}

[1] H. zur Hausen, "Papillomaviruses and cancer: from basic studies to clinical application," Nature Reviews Cancer, vol. 2, no. 5, pp. 342-350, 2002.

[2] L. Coscoy, "Immune evasion by Kaposi's sarcoma-associated herpesvirus," Nature Reviews Immunology, vol. 7, no. 5, pp. 391-401, 2007.

[3] B. Damania, "DNA tumor viruses and human cancer," Trends in Microbiology, vol. 15, no. 1, pp. 38-44, 2007.

[4] E. Klein, L. L. Kis, and G. Klein, "Epstein-Barr virus infection in humans: from harmless to life endangering virus-lymphocyte interactions," Oncogene, vol. 26, no. 9, pp. 1297-1305, 2007.

[5] M. Matsuoka and K.-T. Jeang, "Human T-cell leukaemia virus type 1 (HTLV-1) infectivity and cellular transformation," Nature Reviews Cancer, vol. 7, no. 4, pp. 270-280, 2007.

[6] V. E. Gurtsevitch, "Human oncogenic viruses: hepatitis B and hepatitis $\mathrm{C}$ viruses and their role in hepatocarcinogenesis," Biochemistry, vol. 73, no. 5, pp. 504-513, 2008.

[7] U. Moens and M. Johannessen, "Human polyomaviruses and cancer: expanding repertoire," Journal of the German Society of Dermatology, vol. 6, no. 9, pp. 704-708, 2008.

[8] V. Brower, "Connecting viruses to cancer: how research moves from association to causation," Journal of the National Cancer Institute, vol. 96, no. 4, pp. 256-257, 2004.

[9] D. M. Morens, G. K. Folkers, and A. S. Fauci, "The challenge of emerging and re-emerging infectious diseases," Nature, vol. 430, no. 6996, pp. 242-249, 2004.

[10] World Health Organization, 2008, http://www.who.int/ healthinfo/morttables/en/index.html.

[11] B. R. Cullen, "Viruses and microRNAs," Nature Genetics, vol. 38, supplement 6, pp. S25-S30, 2006.

[12] B. Berkhout and J. Haasnoot, "The interplay between virus infection and the cellular RNA interference machinery," FEBS Letters, vol. 580, no. 12, pp. 2896-2902, 2006.

[13] B. Berkhout and K.-T. Jeang, "RISCy business: microRNAs, pathogenesis, and viruses," Journal of Biological Chemistry, vol. 282, no. 37, pp. 26641-26645, 2007.

[14] J. Haasnoot, E. M. Westerhout, and B. Berkhout, "RNA interference against viruses: strike and counterstrike," Nature Biotechnology, vol. 25, no. 12, pp. 1435-1443, 2007.

[15] W. de Vries and B. Berkhout, "RNAi suppressors encoded by pathogenic human viruses," International Journal of Biochemistry \& Cell Biology, vol. 40, no. 10, pp. 2007-2012, 2008.

[16] B. R. Cullen, "Viral and cellular messenger RNA targets of viral microRNAs," Nature, vol. 457, no. 7228, pp. 421-425, 2009.

[17] Z. Ghosh, B. Mallick, and J. Chakrabarti, "Cellular versus viral microRNAs in host-virus interaction," Nucleic Acid Research, vol. 37, no. 4, pp. 1035-1048, 2009.

[18] M. N. Poy, M. Spranger, and M. Stoffel, "MicroRNAs and the regulation of glucose and lipid metabolism," Diabetes, Obesity and Metabolism, vol. 9, supplement 2, pp. 67-73, 2007.
[19] Y. Zhao and D. Srivastava, "A developmental view of microRNA function," Trends in Biochemical Sciences, vol. 32, no. 4, pp. 189-197, 2007.

[20] D. Baltimore, M. P. Boldin, R. M. O’Connell, D. S. Rao, and K. D. Taganov, "MicroRNAs: new regulators of immune cell development and function," Nature Immunology, vol. 9, no. 8, pp. 839-845, 2008.

[21] F.-B. Gao, "Posttranscriptional control of neuronal development by microRNA networks," Trends in Neurosciences, vol. 31, no. 1, pp. 20-26, 2008.

[22] S. Griffiths-Jones, H. K. Saini, S. van Dongen, and A. J. Enright, "miRBase: tools for microRNA genomics," Nucleic Acids Research, vol. 36, database issue, pp. D154-D158, 2008.

[23] V. Ambros, "The functions of animal microRNAs," Nature, vol. 431, no. 7006, pp. 350-355, 2004.

[24] D. P. Bartel, "MicroRNAs: genomics, biogenesis, mechanism, and function," Cell, vol. 116, no. 2, pp. 281-297, 2004.

[25] E. Gottwein and B. R. Cullen, "Viral and cellular microRNAs as determinants of viral pathogenesis and immunity," Cell Host \& Microbe, vol. 3, no. 6, pp. 375-387, 2008.

[26] J. Brennecke, A. Stark, R. B. Russell, and S. M. Cohen, "Principles of microRNA-target recognition," PLoS Biology, vol. 3, no. 3, article e85, pp. 1-15, 2005.

[27] A. Krek, D. Grün, M. N. Poy, et al., "Combinatorial microRNA target predictions," Nature Genetics, vol. 37, no. 5, pp. 495-500, 2005.

[28] J. Mattes, A. Collison, and P. S. Foster, "Emerging role of microRNAs in disease pathogenesis and strategies for therapeutic modulation," Current Opinion in Molecular Therapeutics, vol. 10, no. 2, pp. 150-157, 2008.

[29] C. C. Esau, "Inhibition of microRNA with antisense oligonucleotides," Methods, vol. 44, no. 1, pp. 55-60, 2008.

[30] J. Elmén, M. Lindow, S. Schütz, et al., "LNA-mediated microRNA silencing in non-human primates," Nature, vol. 452, no. 7189, pp. 896-899, 2008.

[31] K. B. Spurgers, C. M. Sharkey, K. L. Warfield, and S. Bavari, "Oligonucleotide antiviral therapeutics: antisense and RNA interference for highly pathogenic RNA viruses," Antiviral Research, vol. 78, no. 1, pp. 26-36, 2008.

[32] J. Krützfeldt, N. Rajewsky, R. Braich, et al., "Silencing of microRNAs in vivo with 'antagomirs', Nature, vol. 438, no. 7068, pp. 685-689, 2005.

[33] J. Krützfeldt, S. Kuwajima, R. Braich, et al., "Specificity, duplex degradation and subcellular localization of antagomirs," Nucleic Acids Research, vol. 35, no. 9, pp. 28852892, 2007.

[34] J. Mattes, M. Yang, and P. S. Foster, "Regulation of microRNA by antagomirs: a new class of pharmacological antagonists for the specific regulation of gene function?" American Journal of Respiratory Cell and Molecular Biology, vol. 36, no. 1, pp. 812, 2007.

[35] C. Esau, S. Davis, S. F. Murray, et al., "miR-122 regulation of lipid metabolism revealed by in vivo antisense targeting," Cell Metabolism, vol. 3, no. 2, pp. 87-98, 2006.

[36] M. Egholm, O. Buchardt, L. Christensen, et al., "PNA hybridizes to complementary oligonucleotides obeying the Watson-Crick hydrogen-bonding rules," Nature, vol. 365, no. 6446, pp. 566-568, 1993.

[37] M. M. Fabani and M. J. Gait, "miR-122 targeting with LNA/2' -O-methyl oligonucleotide mixmers, peptide nucleic acids (PNA), and PNA-peptide conjugates," RNA, vol. 14, no. 2, pp. 336-346, 2008. 
[38] J. Weiler, J. Hunziker, and J. Hall, "Anti-miRNA oligonucleotides (AMOs): ammunition to target miRNAs implicated in human disease?" Gene Therapy, vol. 13, no. 6, pp. 496-502, 2006.

[39] U. Moens, M. Van Ghelue, and M. Johannessen, "Human polyomaviruses: molecular mechanisms for transformation and their association with cancers," in New Research on Oncogenic Viruses, E. I. Tuneley, Ed., pp. 1-63, Nova Science, New York, NY, USA, 2008.

[40] M. Jiang, J. R. Abend, S. F. Johnson, and M. J. Imperiale, “The role of polyomaviruses in human disease," Virology, vol. 384, no. 2, pp. 266-273, 2009.

[41] T. Allander, K. Andreasson, S. Gupta, et al., "Identification of a third human polyomavirus," Journal of Virology, vol. 81, no. 8, pp. 4130-4136, 2007.

[42] A. M. Gaynor, M. D. Nissen, D. M. Whiley, et al., "Identification of a novel polyomavirus from patients with acute respiratory tract infections," PLoS Pathogens, vol. 3, no. 5, article e64, pp. 1-10, 2007.

[43] H. Feng, M. Shuda, Y. Chang, and P. S. Moore, "Clonal integration of a polyomavirus in human Merkel cell carcinoma," Science, vol. 319, no. 5866, pp. 1096-1100, 2008.

[44] U. Moens and O. P. Rekvig, "Molecular biology of BK virus and clinical aspects of BK virus renal infection," in Human Polyomaviruses: Molecular and Clinical Perspectives, K. Khalili and G. L. Stoner, Eds., pp. 359-408, Wiley Liss, New York, NY, USA, 2001.

[45] C. S. Sullivan, A. T. Grundhoff, S. Tevethia, J. M. Pipas, and D. Ganem, "SV40-encoded microRNAs regulate viral gene expression and reduce susceptibility to cytotoxic T cells," Nature, vol. 435, no. 7042, pp. 682-686, 2005.

[46] G. J. Seo, L. H. L. Fink, B. O’Hara, W. J. Atwood, and C. S. Sullivan, "Evolutionarily conserved function of a viral microRNA," Journal of Virology, vol. 82, no. 20, pp. 9823 9828, 2008.

[47] G. J. Seo, C. J. Chen, and C. S. Sullivan, "Merkel cell polyomavirus encodes a microRNA with the ability to autoregulate viral gene expression," Virology, vol. 383, no. 2, pp. 183-187, 2009.

[48] J. L. Umbach, M. F. Kramer, I. Jurak, H. W. Karnowski, D. M. Coen, and B. R. Cullen, "MicroRNAs expressed by herpes simplex virus 1 during latent infection regulate viral mRNAs," Nature, vol. 454, no. 7205, pp. 780-783, 2008.

[49] W. Dunn, P. Trang, Q. Zhong, E. Yang, C. van Belle, and F. Liu, "Human cytomegalovirus expresses novel microRNAs during productive viral infection," Cellular Microbiology, vol. 7, no. 11, pp. 1684-1695, 2005.

[50] F. Grey and J. Nelson, "Identification and function of human cytomegalovirus microRNAs," Journal of Clinical Virology, vol. 41, no. 3, pp. 186-191, 2008.

[51] S. Pfeffer, M. Zavolan, F. A. Grässer, et al., "Identification of virus-encoded microRNAs," Science, vol. 304, no. 5671, pp. 734-736, 2004.

[52] L. He, J. M. Thomson, M. T. Hemann, et al., "A microRNA polycistron as a potential human oncogene," Nature, vol. 435, no. 7043, pp. 828-833, 2005.

[53] C. Seeger, F. Zoulin, and W. S. Mason, "Hepadnaviruses," in Fields' Virology, D. M. Knipe and P. M. Howeley, Eds., pp. 2847-2888, Lippincott Williams and Wilkins, Philadelphia, Pa, USA, 2007.

[54] W.-B. Jin, F.-L. Wu, D. Kong, and A.-G. Guo, "HBV-encoded microRNA candidate and its target," Computational Biology and Chemistry, vol. 31, no. 2, pp. 124-126, 2007.
[55] M. A. Wainberg and K.-T. Jeang, "25 years of HIV-1 research-progress and perspectives," BMC Medicine, vol. 6, article 31, pp. 1-7, 2008.

[56] L. B. Ludwig, "RNA silencing and HIV: a hypothesis for the etiology of the severe combined immunodeficiency induced by the virus," Retrovirology, vol. 5, article 79, pp. 1-13, 2008.

[57] S. Omoto, M. Ito, Y. Tsutsumi, et al., "HIV-1 nef suppression by virally encoded microRNA," Retrovirology, vol. 1, p. 44, 2004.

[58] X. Cai, G. Li, L. A. Laimins, and B. R. Cullen, "Human papillomavirus genotype 31 does not express detectable microRNA levels during latent or productive virus replication," Journal of Virology, vol. 80, no. 21, pp. 10890-10893, 2006.

[59] W. S. M. Wold and M. S. Horowitz, "Adenoviruses," in Fields' Virology, D. M. Knipe and P. M. Howeley, Eds., pp. 23952436, Lippincott Williams and Wilkins, Philadelphia, Pa, USA, 2007.

[60] M. B. Mathews, "Structure, function and evolution of adenovirus virus-associated RNAs," Current Topics in Microbiology and Immunology, vol. 199, part 2, pp. 173-187, 1995.

[61] M. G. Andersson, P. C. J. Haasnoot, N. Xu, S. Berenjian, B. Berkhout, and G. Akusjärvi, "Suppression of RNA interference by adenovirus virus-associated RNA," Journal of Virology, vol. 79, no. 15, pp. 9556-9565, 2005.

[62] O. Aparicio, N. Razquin, M. Zaratiegui, I. Narvaiza, and P. Fortes, "Adenovirus virus-associated RNA is processed to functional interfering RNAs involved in virus production," Journal of Virology, vol. 80, no. 3, pp. 1376-1384, 2006.

[63] M. Sano, Y. Kato, and K. Taira, "Sequence-specific interference by small RNAs derived from adenovirus VAI RNA," FEBS Letters, vol. 580, no. 6, pp. 1553-1564, 2006.

[64] P. E. Pellet and B. Roizman, "The family Herpesviridae: a brief introduction," in Fields' Virology, D. M. Knipe and P. M. Howeley, Eds., pp. 2479-2500, Lippincott Williams and Wilkins, Philadelphia, Pa, USA, 2007.

[65] S. Pfeffer, A. Sewer, M. Lagos-Quintana, et al., "Identification of microRNAs of the herpesvirus family," Nature Methods, vol. 2, no. 4, pp. 269-276, 2005.

[66] X. Cai, A. Schäfer, S. Lu, et al., "Epstein-Barr virus microRNAs are evolutionarily conserved and differentially expressed," PLoS Pathogens, vol. 2, no. 3, article e23, pp. 112, 2006.

[67] A. Gupta, J. J. Gartner, P. Sethupathy, A. G. Hatzigeorgiou, and N. W. Fraser, "Anti-apoptotic function of a microRNA encoded by the HSV-1 latency-associated transcript," Nature, vol. 442, no. 7098, pp. 82-85, 2006.

[68] S. Tang, A. S. Bertke, A. Patel, K. Wang, J. I. Cohen, and P. R. Krause, "An acutely and latently expressed herpes simplex virus 2 viral microRNA inhibits expression of ICP34.5, a viral neurovirulence factor," Proceedings of the National Academy of Sciences of the United States of America, vol. 105, no. 31, pp. 10931-10936, 2008.

[69] C. Cui, A. Griffiths, G. Li, et al., "Prediction and identification of herpes simplex virus 1-encoded microRNAs," Journal of Virology, vol. 80, no. 11, pp. 5499-5508, 2006.

[70] S. Tang, A. Patel, and P. R. Krause, "Novel less-abundant viral miRNAs encoded by herpes simplex virus 2 latencyassociated transcript and their roles in regulating ICP34.5 and ICP0 mRNAs," Journal of Virology, vol. 83, no. 3, pp. 1433-1442, 2009. 
[71] R. Grassmann and K.-T. Jeang, "The roles of microRNAs in mammalian virus infection," Biochimica et Biophysica Acta, vol. 1779, no. 11, pp. 706-711, 2008.

[72] N. Stern-Ginossar, N. Elefant, A. Zimmermann, et al., "Host immune system gene targeting by a viral miRNA," Science, vol. 317, no. 5836, pp. 376-381, 2007.

[73] E. Murphy, J. Vaníček, H. Robins, T. Shenk, and A. J. Levine, "Suppression of immediate-early viral gene expression by herpesvirus-coded microRNAs: implications for latency," Proceedings of the National Academy of Sciences of the United States of America, vol. 105, no. 14, pp. 5453-5458, 2008.

[74] F. Grey, H. Meyers, E. A. White, D. H. Spector, and J. Nelson, "A human cytomegalovirus-encoded microRNA regulates expression of multiple viral genes involved in replication," PloS Pathogens, vol. 3, article e163, no. 11, pp. 1-10, 2007.

[75] A. Grundhoff, C. S. Sullivan, and D. Ganem, "A combined computational and microarray-based approach identifies novel microRNAs encoded by human gammaherpesviruses," RNA, vol. 12, no. 5, pp. 733-750, 2006.

[76] A. K. F. Lo, K. F. To, K. W. Lo, et al., "Modulation of LMP1 protein expression by EBV-encoded microRNAs," Proceedings of the National Academy of Sciences of the United States of America, vol. 104, no. 41, pp. 16164-16169, 2007.

[77] S. Barth, T. Pfuhl, A. Mamiani, et al., "Epstein-Barr virusencoded microRNA miR-BART2 down-regulates the viral DNA polymerase BALF5," Nucleic Acids Research, vol. 36, no. 2, pp. 666-675, 2008.

[78] E. Y. Choy, K. L. Siu, K. H. Kok, et al., "An Epstein-Barr virus-encoded microRNA targets PUMA to promote host cell survival," The Journal of Experimental Medicine, vol. 205, no. 11, pp. 2551-2560, 2008.

[79] T. Xia, A. O'Hara, I. Araujo, et al., "EBV microRNAs in primary lymphomas and targeting of CXCL-11 by ebv-mirBHRF1-3," Cancer Research, vol. 68, no. 5, pp. 1436-1442, 2008.

[80] M. A. Samols, R. L. Skalsky, A. M. Maldonado, et al., "Identification of cellular genes targeted by KSHV-encoded microRNA," PLoS Pathogens, vol. 3, no. 5, article e65, pp. 18, 2007.

[81] E. Gottwein, N. Mukherjee, C. Sachse, et al., "A viral microRNA functions as an orthologue of cellular miR-155," Nature, vol. 450, no. 7172, pp. 1096-1099, 2007.

[82] R. L. Skalsky, M. A. Samols, K. B. Plaisance, et al., "Kaposi’s sarcoma-associated herpesvirus encodes an ortholog of miR155," Journal of Virology, vol. 81, no. 23, pp. 12836-12845, 2007.

[83] Z. Klase, P. Kale, R. Winograd, et al., "HIV-1 TAR element is processed by Dicer to yield a viral micro-RNA involved in chromatin remodeling of the viral LTR," BMC Molecular Biology, vol. 8, article 63, pp. 1-19, 2007.

[84] D. L. Ouellet, I. Plante, P. Landry, et al., "Identification of functional microRNAs released through asymmetrical processing of HIV-1 TAR element," Nucleic Acids Research, vol. 36, no. 7, pp. 2353-2365, 2008.

[85] Y. Bennasser, S.-Y. Le, M. L. Yeung, and K.-T. Jeang, "HIV1 encoded candidate micro-RNAs and their cellular targets," Retrovirology, vol. 1, article 43, pp. 1-5, 2004.

[86] J. L. Foster and J. V. Garcia, "HIV-1 Nef: at the crossroads," Retrovirology, vol. 5, article 84, pp. 1-13, 2008.

[87] K. J. Purzycka and R. W. Adamiak, "The HIV-2 TAR RNA domain as a potential source of viral-encoded miRNA. A reconnaissance study," Nucleic Acids Symposium Series, vol. 52, no. 1, pp. 511-512, 2008.
[88] J. Lin and B. R. Cullen, "Analysis of the interaction of primate retroviruses with the human RNA interference machinery," Journal of Virology, vol. 81, no. 22, pp. 12218-12226, 2007.

[89] B. Roizman, D. M. Knipe, and R. J. Whitley, "Herpes simplex viruses," in Fields' Virology, D. M. Knipe and P. M. Howeley, Eds., pp. 2501-2602, Lippincott Williams and Wilkins, Philadelphia, Pa, USA, 2007.

[90] B. Sugden, "Virology: micro mystery solution," Nature, vol. 442, no. 7098, pp. 33-34, 2006.

[91] A. Gupta, J. J. Gartner, P. Sethupathy, A. G. Hatzigeorgiou, and N. W. Fraser, "Anti-apoptotic function of a microRNA encoded by the HSV-1 latency-associated transcript," Nature, vol. 451, no. 7178, p. 600, 2008.

[92] R. Gupta, T. Warren, and A. Wald, "Genital herpes," The Lancet, vol. 370, no. 9605, pp. 2127-2137, 2007.

[93] A. Orvedahl, D. Alexander, Z. Tallóczy, et al., "HSV-1 ICP34.5 confers neurovirulence by targeting the beclin 1 autophagy protein," Cell Host \& Microbe, vol. 1, no. 1, pp. 23-35, 2007.

[94] J. I. Cohen, S. E. Straus, and A. M. Arvin, "Varicellazoster virus," in Fields' Virology, D. M. Knipe and P. M. Howeley, Eds., pp. 2733-2818, Lippincott Williams and Wilkins, Philadelphia, Pa, USA, 2007.

[95] F. Grey, L. Hook, and J. Nelson, "The functions of herpesvirus-encoded microRNAs," Medical Microbiology and Immunology, vol. 197, no. 2, pp. 261-267, 2008.

[96] J. A. Nelson, "Small RNAs and large DNA viruses," The New England Journal of Medicine, vol. 357, no. 25, pp. 2630-2632, 2007.

[97] L. S. Young and A. B. Rickinson, "Epstein-Barr virus: 40 years on," Nature Reviews Cancer, vol. 4, no. 10, pp. 757-768, 2004.

[98] L. Xing and E. Kieff, "Epstein-Barr virus BHRF1 microand stable RNAs during latency III and after induction of replication," Journal of Virology, vol. 81, no. 18, pp. 99679975, 2007.

[99] D. N. Kim, H.-S. Chae, S. T. Oh, et al., "Expression of viral microRNAs in Epstein-Barr virus-associated gastric carcinoma," Journal of Virology, vol. 81, no. 2, pp. 1033-1036, 2007.

[100] R. H. Edwards, A. R. Marquitz, and N. Raab-Traub, "EpsteinBarr virus BART microRNAs are produced from a large intron prior to splicing," Journal of Virology, vol. 82, no. 18, pp. 9094-9106, 2008.

[101] M. M. Brinkmann and T. F. Schulz, "Regulation of intracellular signalling by the terminal membrane proteins of members of the Gammaherpesvirinae," Journal of General Virology, vol. 87, no. 5, pp. 1047-1074, 2006.

[102] U. Moens and M. Johannessen, "Mechanisms by which viral proteins of human DNA tumor viruses hijack the cell cycle," in DNA Tumor Viruses, H. E. Tao, Ed., pp. 1-48, Nova Science, New York, NY, USA, 2008.

[103] P. Sethupathy, M. Megraw, and A. G. Hatzigeorgiou, "A guide through present computational approaches for the identification of mammalian microRNA targets," Nature Methods, vol. 3, no. 11, pp. 881-886, 2006.

[104] X. Yang, Y. Chu, Y. Wang, Q. Guo, and S. Xiong, "Vaccination with IFN-inducible T cell $\alpha$ chemoattractant (ITAC) genemodified tumor cell attenuates disseminated metastases of circulating tumor cells," Vaccine, vol. 24, no. 15, pp. 29662974, 2006.

[105] P. J. Hensbergen, P. G. Wijnands, M. W. J. Schreurs, R. J. Scheper, R. Willemze, and C. P. Tensen, "The CXCR3 targeting chemokine CXCL11 has potent antitumor activity in vivo involving attraction of $\mathrm{CD}^{+} \mathrm{T}$ lymphocytes but not 
inhibition of angiogenesis," Journal of Immunotherapy, vol. 28, no. 4, pp. 343-351, 2005.

[106] D. Ganem, "Kaposi's sarcoma-associated virus," in Fields' Virology, D. M. Knipe and P. M. Howeley, Eds., pp. 28472888, Lippincott Williams and Wilkins, Philadelphia, Pa, USA, 2007.

[107] V. Marshall, T. Parks, R. Bagni, et al., "Conservation of viraly encoded microRNAs in Kaposi sarcoma-associated herpesvirus in primary effusion lymphoma cell lines and in patients with Kaposi sarcoma or multicentric Castleman disease," The Journal of Infectious Diseases, vol. 195, no. 5, pp. 645-659, 2007.

[108] D. Ganem and J. Ziegelbauer, "MicroRNAs of Kaposi's sarcoma-associated herpes virus," Seminars in Cancer Biology, vol. 18, no. 6, pp. 437-440, 2008.

[109] J. M. Ziegelbauer, C. S. Sullivan, and D. Ganem, “Tandem array-based expression screens identify host mRNA targets of virus-encoded microRNAs," Nature Genetics, vol. 41, no. 1, pp. 130-134, 2009.

[110] G. A. Calin and C. M. Croce, "MicroRNA signatures in human cancers," Nature Reviews Cancer, vol. 6, no. 11, pp. 857-866, 2006.

[111] S. Costinean, N. Zanesi, Y. Pekarsky, et al., "Pre-B cell proliferation and lymphoblastic leukemia/high-grade lymphoma in E $\mu$-miR155 transgenic mice," Proceedings of the National Academy of Sciences of the United States of America, vol. 103, no. 18, pp. 7024-7029, 2006.

[112] J. Sun, M. Brand, Y. Zenke, S. Tashiro, M. Groudine, and K. Igarashi, "Heme regulates the dynamic exchange of Bach1 and NF-E2-related factors in the Maf transcription factor network," Proceedings of the National Academy of Sciences of the United States of America, vol. 101, no. 6, pp. 1461-1466, 2004.

[113] E. Shaulian and M. Karin, "AP-1 as a regulator of cell life and death," Nature Cell Biology, vol. 4, no. 5, pp. E131-E136, 2002.

[114] A. Cimmino, G. A. Calin, M. Fabbri, et al., " $m i R-15$ and $m i R-$ 16 induce apoptosis by targeting BCL2," Proceedings of the National Academy of Sciences of the United States of America, vol. 102, no. 39, pp. 13944-13949, 2005.

[115] M. S. Weinberg and K. V. Morris, "Are viral-encoded microRNAs mediating latent HIV-1 infection?" DNA and Cell Biology, vol. 25, no. 4, pp. 223-231, 2006.

[116] M. Barboric and B. M. Peterlin, "A new paradigm in eukaryotic biology: HIV Tat and the control of transcriptional elongation," PLoS Biology, vol. 3, no. 2, article e76, pp. 200203, 2005.

[117] L. B. Ludwig, J. L. Ambrus Jr., K. A. Krawczyk, et al., "Human Immunodeficiency Virus-Type 1 LTR DNA contains an intrinsic gene producing antisense RNA and protein products," Retrovirology, vol. 3, article 80, pp. 1-20, 2006.

[118] S. Omoto and Y. R. Fujii, "Regulation of human immunodeficiency virus 1 transcription by nef microRNA," Journal of General Virology, vol. 86, no. 3, pp. 751-755, 2005.

[119] J. P. Couturier and R. S. Root-Bernstein, "HIV may produce inhibitory microRNAs (miRNAs) that block production of CD28, CD4 and some interleukins," Journal of Theoretical Biology, vol. 235, no. 2, pp. 169-184, 2005.

[120] C. L. Jopling, M. Yi, A. M. Lancaster, S. M. Lemon, and P. Sarnow, "Molecular biology: modulation of hepatitis $\mathrm{C}$ virus
RNA abundance by a liver-specific microRNA," Science, vol. 309, no. 5740, pp. 1577-1581, 2005.

[121] G. Randall, M. Panis, J. D. Cooper, et al., "Cellular cofactors affecting hepatitis $\mathrm{C}$ virus infection and replication," Proceedings of the National Academy of Sciences of the United States of America, vol. 104, no. 31, pp. 12884-12889, 2007.

[122] J. Anderson, C. Schiffer, S. K. Lee, and R. Swanstrom, "Viral protease inhibitors," Handbook of Experimental Pharmacology, vol. 189, pp. 85-110, 2009.

[123] E. De Clercq and J. Neyts, "Antiviral agents acting as DNA or RNA chain terminators," Handbook of Experimental Pharmacology, vol. 189, pp. 53-84, 2009.

[124] P. Kumar, H.-S. Ban, S.-S. Kim, et al., "T cell-specific siRNA delivery suppresses HIV-1 infection in humanized mice," Cell, vol. 134, no. 4, pp. 577-586, 2008.

[125] C. Rauschhuber, H. Xu, F. H. Salazar, P. L. Marion, and A. Ehrhardt, "Exploring gene-deleted adenoviral vectors for delivery of short hairpin RNAs and reduction of hepatitis B virus infection in mice," The Journal of Gene Medicine, vol. 10, no. 8, pp. 878-889, 2008.

[126] F. Eckstein, "The versatility of oligonucleotides as potential therapeutics," Expert Opinion on Biological Therapy, vol. 7, no. 7, pp. 1021-1034, 2007.

[127] D. H. Le, "RNA-interference therapy for HBV infection enters Phase I clinical trial," Expert Review of Anti-Infective Therapy, vol. 6, no. 1, pp. 5-8, 2008.

[128] E. M. Westerhout, M. Ooms, M. Vink, A. T. Das, and B. Berkhout, "HIV-1 can escape from RNA interference by evolving an alternative structure in its RNA genome," Nucleic Acids Research, vol. 33, no. 2, pp. 796-804, 2005.

[129] D. Boden, O. Pusch, and B. Ramratnam, "Overcoming HIV1 resistance to RNA interference," Frontiers in Bioscience, vol. 12, pp. 3104-3116, 2007.

[130] S. He, Z. Yang, G. Skogerbo, et al., "The properties and functions of virus encoded microRNA, siRNA, and other small noncoding RNAs," Critical Reviews in Microbiology, vol. 34, no. 3-4, pp. 175-188, 2008.

[131] N. Blow, "Small RNAs: delivering the future," Nature, vol. 450, no. 7172, pp. 1117-1120, 2007.

[132] M. Scherr, L. Venturini, K. Battmer, et al., "Lentivirusmediated antagomir expression for specific inhibition of miRNA function," Nucleic Acids Research, vol. 35, no. 22, article e149, pp. 1-9, 2007.

[133] E. R. Rayburn and R. Zhang, "Antisense, RNAi, and gene silencing strategies for therapy: mission possible or impossible?” Drug Discovery Today, vol. 13, no. 11-12, pp. 513-521, 2008.

[134] L. L. Snyder, J. M. Esser, C. J. Pachuk, and L. F. Steel, "Vector design for liver-specific expression of multiple interfering RNAs that target hepatitis B virus transcripts," Antiviral Research, vol. 80, no. 1, pp. 36-44, 2008.

[135] M. Dimitrova, C. Affolter, F. Meyer, et al., "Sustained delivery of siRNAs targeting viral infection by cell-degradable multilayered polyelectrolyte films," Proceedings of the National Academy of Sciences of the United States of America, vol. 105, no. 42, pp. 16320-16325, 2008.

[136] Y.-J. Zhang, K.-Y. Wang, D. A. Stein, et al., "Inhibition of replication and transcription activator and latencyassociated nuclear antigen of Kaposi's sarcoma-associated herpesvirus by morpholino oligomers," Antiviral Research, vol. 73, no. 1, pp. 12-23, 2007. 
[137] I. Lebars, T. Richard, C. Di Primo, and J.-J. Toulmé, "LNA derivatives of a kissing aptamer targeted to the transactivating responsive RNA element of HIV-1," Blood Cells, Molecules, and Diseases, vol. 38, no. 3, pp. 204-209, 2007.

[138] J. S. Eisen and J. C. Smith, "Controlling morpholino experiments: don't stop making antisense," Development, vol. 135, no. 10, pp. 1735-1743, 2008. 

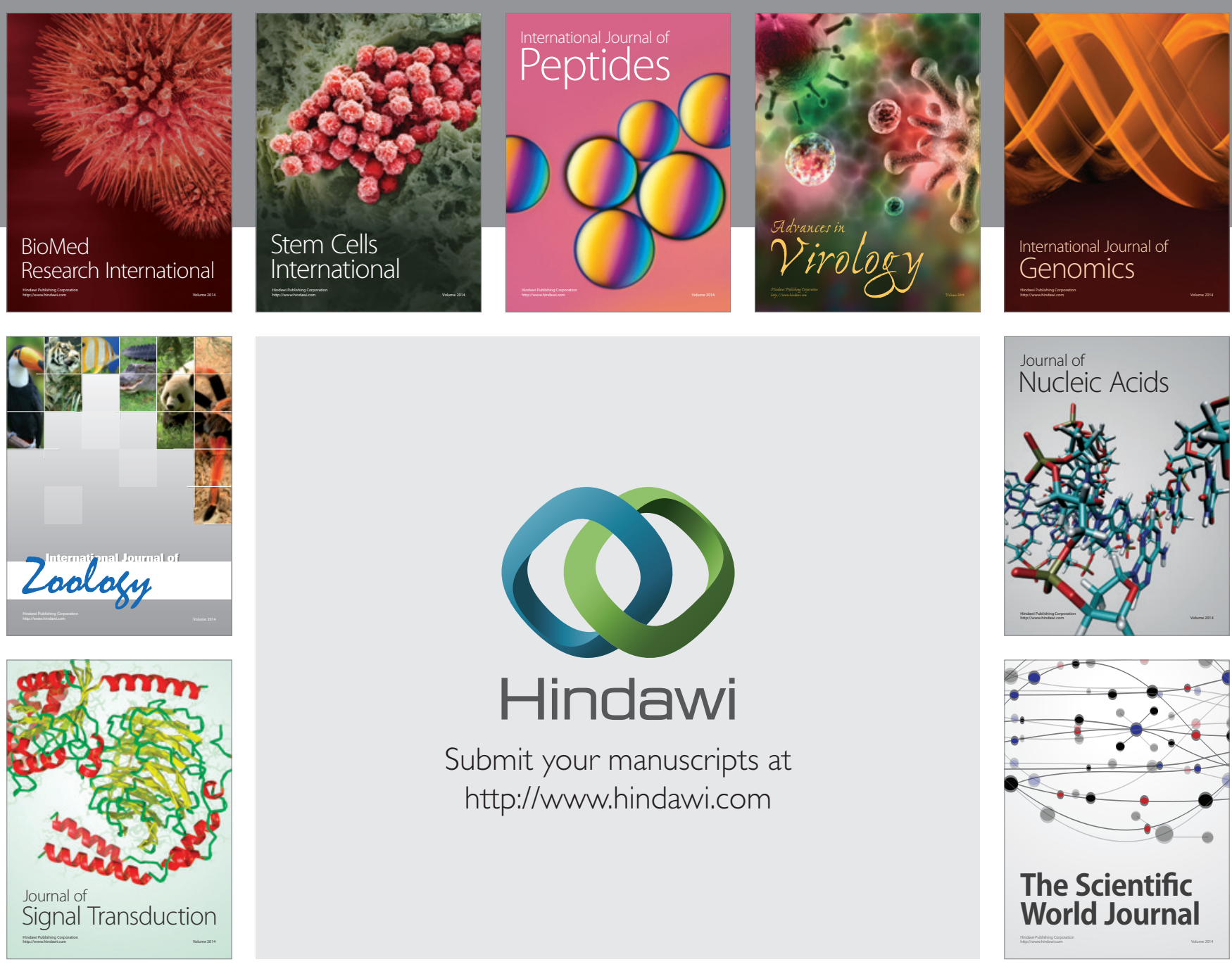

Submit your manuscripts at

http://www.hindawi.com
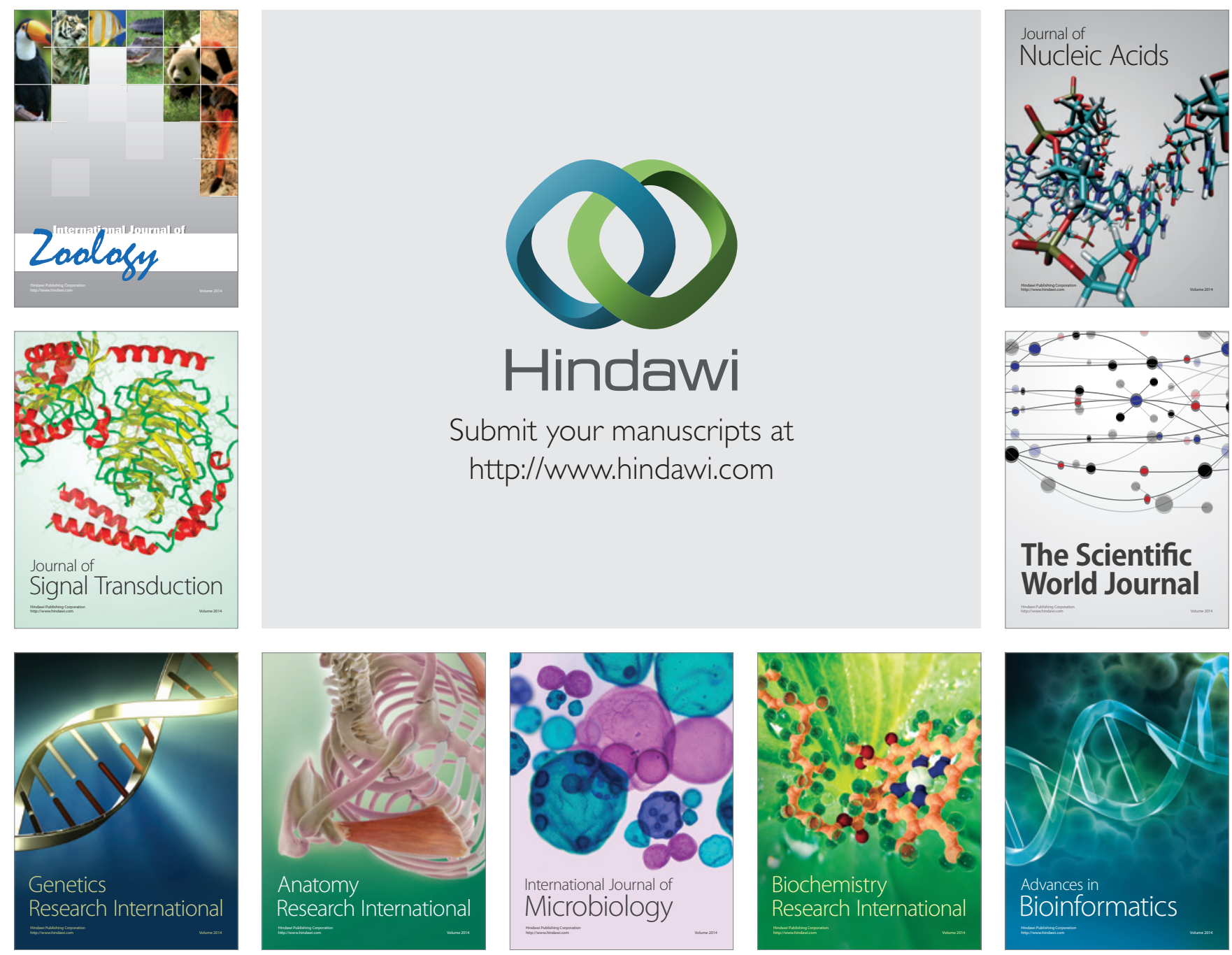

The Scientific World Journal
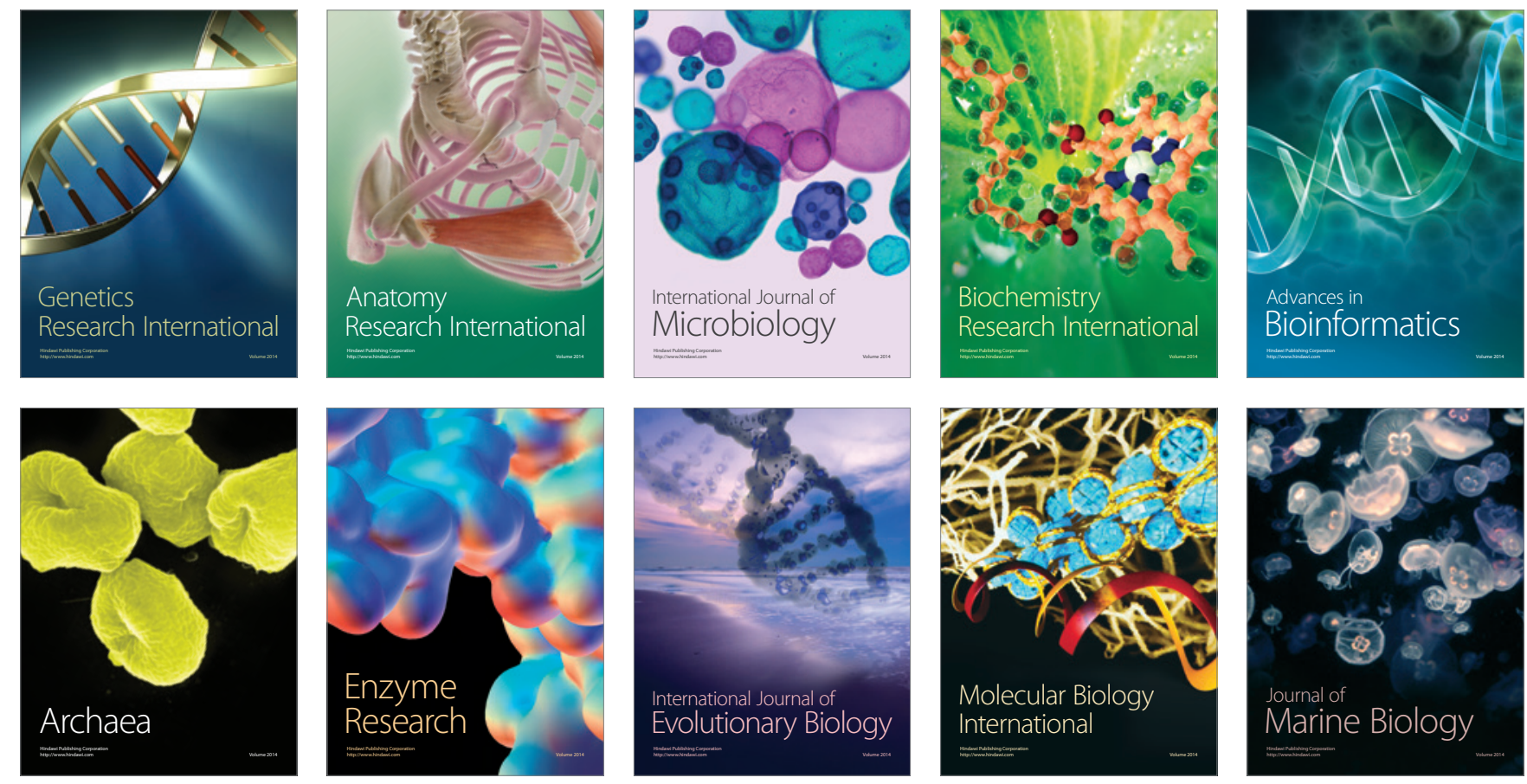